Article

\title{
Synthesis and Antimicrobial Evaluation of 1-[(2-Substituted phenyl)carbamoyl]naphthalen-2-yl Carbamates $^{\dagger}$
}

Tomas Gonec ${ }^{1, *}$, Sarka Pospisilova ${ }^{2}$, Lucie Holanova ${ }^{3}$, Josef Stranik ${ }^{1}$, Aneta Cernikova ${ }^{1}$, Valeria Pudelkova ${ }^{2}$, Jiri Kos ${ }^{1}$, Michal Oravec ${ }^{4}$, Peter Kollar ${ }^{3}$, Alois Cizek ${ }^{2}$ and Josef Jampilek ${ }^{5, *}$

1 Department of Chemical Drugs, Faculty of Pharmacy, University of Veterinary and Pharmaceutical Sciences, Palackeho 1, Brno 61242, Czech Republic; F15334@vfu.cz (J.S.); cernikova.aneta@gmail.com (A.C.); jurd@email.cz (J.K.)

2 Department of Infectious Diseases and Microbiology, Faculty of Veterinary Medicine, University of Veterinary and Pharmaceutical Sciences, Palackeho 1, Brno 61242, Czech Republic; sharka.pospisilova@gmail.com (S.P.); valeria.pudelkova@gmail.com (V.P.); cizeka@vfu.cz (A.C.)

3 Department of Human Pharmacology and Toxicology, Faculty of Pharmacy, University of Veterinary and Pharmaceutical Sciences, Palackeho 1, Brno 61242, Czech Republic; lucieholanova9@gmail.com (L.H.); kollarp@vfu.cz (P.K.)

4 Global Change Research Institute CAS, Belidla 986/4a, Brno 60300, Czech Republic; oravec.m@czechglobe.cz

5 Department of Pharmaceutical Chemistry, Faculty of Pharmacy, Comenius University, Odbojarov 10, Bratislava 83232, Slovakia

* Correspondence: t.gonec@seznam.cz (T.G.); josef.jampilek@gmail.com (J.J.); Tel.: +420-541-562-938 (T.G.)

+ Preliminary Results Were Presented at the 8th Central European Conference "Chemistry towards Biology" (CTB-2016), Brno, Czech Republic, 28 August-1 September 2016 (Paper P-18).

Academic Editor: Derek J. McPhee

Received: 24 August 2016; Accepted: 5 September 2016; Published: 7 September 2016

\begin{abstract}
Series of thirteen 1-[(2-chlorophenyl)carbamoyl]naphthalen-2-yl carbamates and thirteen 1-[(2-nitrophenyl)carbamoyl]naphthalen-2-yl carbamates with alkyl/cycloalkyl/arylalkyl chains were prepared and characterized. Primary in vitro screening of the synthesized compounds was performed against Staphylococcus aureus, two methicillin-resistant S. aureus strains, Mycobacterium marinum, and M. kansasii. 1-[(2-Chlorophenyl)carbamoyl]naphthalen-2-yl ethylcarbamate and 1-[(2-nitrophenyl) carbamoyl]naphthalen-2-yl ethylcarbamate showed antistaphylococcal (MICs $=42 \mu \mathrm{M}$ against MRSA) and antimycobacterial (MICs $=21 \mu \mathrm{M}$ ) activity against the tested strains comparable with or higher than that of the standards ampicillin and isoniazid. In the case of bulkier carbamate tails ( $\mathrm{R}>$ propyl/isopropyl), the activity was similar (MICs ca. $70 \mu \mathrm{M}$ ). Screening of the cytotoxicity of both of the most effective compounds was performed using THP-1 cells, and no significant lethal effect was observed $\left(\mathrm{LD}_{50}>30 \mu \mathrm{M}\right)$. The structure-activity relationships are discussed.
\end{abstract}

Keywords: carbamates; hydroxynaphthalene-carboxamides; in vitro antibacterial activity; in vitro antimycobacterial activity; in vitro cytotoxicity assay; structure-activity relationships

\section{Introduction}

Infectious diseases represent an increasing worldwide threat. The number of untreatable diseases decreased after the 1950s due to the introduction of new antimicrobial agents. However, since the 1980s, morbidity has risen again. The increase in the number of new infections is caused by general immunosuppression, a significant increase in the number of diabetic or HIV-positive patients, and the development of resistance to commonly used drugs. The resistance of common pathogens to first-choice drugs increased by up to $100 \%$ during the last few decades. Moreover, the resistance of some strains to second- or third-choice drugs can be found. Development of cross-resistant and multidrug-resistant 
strains is a serious global problem. Selection of resistant pathogens is especially caused by irrational and unavailing application of anti-invasive agents in human, veterinary medicine, and in agriculture [1-4]. Resistance may complicate the treatment of infections regardless of how mild these infections were at the early stage [5,6]. This increasing resistance highlights the urgency of designing new effective anti-invasive drugs and developing strategies focused on overcoming drug resistance [5-9].

The discovery of salicylanilides dates back to early phenol applications; currently, salicylanilides are well-known organic compounds exhibiting a broad spectrum of biological activities such as anthelmintic, antibacterial, antimycobacterial, and antiviral, among others. Salicylanilides have been described to affect a wide range of targets, although the appropriate mechanism of action responsible for overall biological activities of these compounds has not been proposed so far. Thus, salicylanilides seem to be promising candidates for antibacterial agents, which could be a solution to the resistance challenges [10-17].

In addition, the presence of an amide (-CONH-) or carbamate (-OCONH-) group with a hydrophobic residue in its close vicinity is characteristic not only of a number of clinically used drugs [18], but also applied pesticides [19]. These moieties are important functional groups that are able, due to their electron properties, to interact and bind with a number of enzymes/receptors and, by means of these target sites, affect the biological response. The properties of the amide and the carbamate moieties can easily be modified by various substitutions [20,21]. Therefore, the reason for the widespread occurrence of amides and carbamates among new biologically active compounds is obvious [22-36].

1-[(2-Substituted phenyl)carbamoyl]naphthalen-2-yl carbamates, described in the present work, can be considered as cyclic analogues of salicylanilides that have expressed promising results as potential antibacterial and antimycobacterial agents ([14-17], and refs. therein). Pattern compounds of these carbamates-N-(2-chlorophenyl)-2-hydroxynaphthalene-1-carboxamide (1) and N-(2-nitrophenyl)-2hydroxynaphthalene-1-carboxamide (2) showed antimycobacterial or antibacterial activity with insignificant cytotoxicity on human cells in the previous screening [30]; therefore, the aim of this contribution was to describe the preparation of various alkyl, cycloalkyl, and arylalkyl carbamates and the investigation of their antimicrobial activity.

\section{Results and Discussion}

\subsection{Chemistry}

All the studied compounds were prepared according to Scheme 1 . In the first step, N-(2-chlorophenyl)-2-hydroxynaphthalene-1-carboxamide (1) and N-(2-nitrophenyl)-2-hydroxynaphthalene-1-carboxamide (2) were synthesized by the microwave-assisted method [30]. In the second step, a modified method using triethylamine for activation of the phenolic group was used [24]. The addition of activated compounds 1 and $\mathbf{2}$ to appropriate alkyl, cycloalkyl, and arylalkyl carbamates yielded a series of thirteen 1-[(2-chlorophenyl)carbamoyl]naphthalen-2-yl carbamates 3-15 and thirteen 1-[(2-nitrophenyl)carbamoyl]naphthalen-2-yl carbamates 16-28.

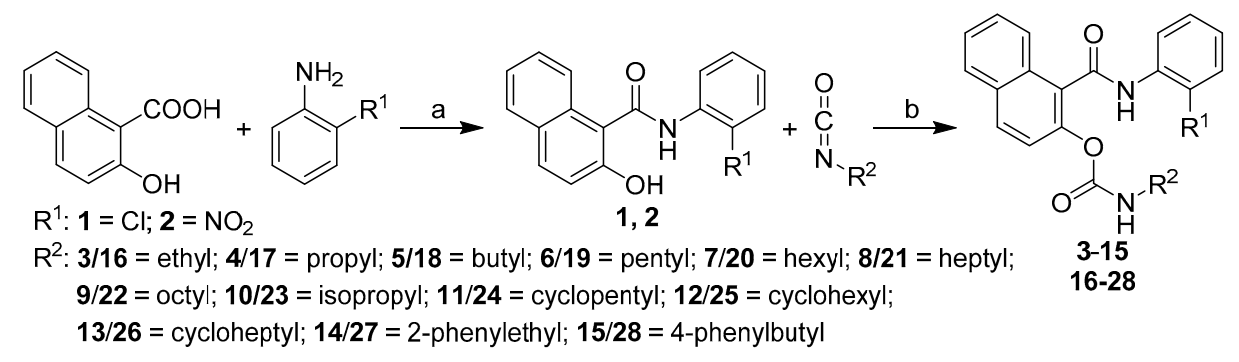

Scheme 1. Synthesis of 1-[(2-chlorophenyl)carbamoyl]naphthalen-2-yl carbamates 3-15 and 1-[(2-nitrophenyl)carbamoyl]naphthalen-2-yl carbamates 16-28. Reagents and conditions: (a) $\mathrm{PCl}_{3}$, chlorobenzene, MW; (b) TEA, acetonitrile, ambient temperature. 
In a number of studies examining the biological activity of potential drugs, the relationship between lipophilicity or other descriptors and their potency have been investigated. In the current investigation, the calculated lipophilicity $(\log P)$ of the compounds as well as the electronic parameters and molar volume of $\mathrm{R}^{2}$ substituents (see Table 1 ) were used to determine if these factors play a role in their biological activity. All the predicted molecular descriptors were calculated using the ACD/Percepta ver. 2012 program, see Table 1. The lipophilicity, expressed as $\log P$ values, of the chlorine substituted compounds 1, 3-15 was higher (ranged from 3.94 to 5.75) than that of the nitro substituted derivatives 2, 16-28 (ranged from 3.58 to 5.55). Lipophilicity increases with lengthening of the alkyl tail. Isopropyl showed a lower lipophilicity value than propyl. Significantly lower lipophilicity values were calculated for the cycloalkyl derivatives compared with their $N$-alkyl isomers. For individual $\mathrm{R}^{2}$ substituents, alkyl/cycloalkyl/arylalkyl tails of the discussed compounds, and also electronic properties expressed as electronic constants $\sigma^{*}$ were predicted; they ranged from -0.25 to 0.08 . The electronic parameters (expressed as Hammett's $\sigma$ parameters) of the 2-Cl moiety (compound 1) and the 2- $\mathrm{NO}_{2}$ moiety (compound 2) were 0.22 and 0.77 , respectively. Molar volume $\mathrm{MV}\left[\mathrm{cm}^{3}\right]$, a parameter representing the bulk of $\mathrm{R}^{2}$ substituents (i.e., tail length/branching) of each compound, was also calculated for the hydrophobic tail.

Table 1. Structures of the discussed anilides 1, 2 and carbamates 3-28; calculated values of $\log P$, electronic constants $\sigma^{*}$, and molar volume (MV $\left.\left[\mathrm{cm}^{3}\right]\right)$ of $\mathrm{R}^{2}$ substituents; in vitro antibacterial activity (MIC) of the compounds in comparison with the ampicillin (APC) standard; in vitro antimycobacterial activity (MIC) of the compounds in comparison with the isoniazid (INH) standard and in vitro cytotoxicity assay $\left(\mathrm{LD}_{50}\right)$ of the chosen compounds.

\begin{tabular}{|c|c|c|c|c|c|c|c|c|c|c|c|}
\hline \multirow{2}{*}{ Compd. } & \multirow{2}{*}{$\mathbf{R}^{1}$} & \multirow{2}{*}{$\mathbf{R}^{2}$} & \multirow{2}{*}{$\log P^{a}$} & \multirow{2}{*}{$\mathrm{MV}_{\mathrm{R} 2}{ }^{\mathrm{a}}\left[\mathrm{cm}^{3}\right]$} & \multirow{2}{*}{$\sigma^{*} 2^{a}$} & \multicolumn{5}{|c|}{$\mathrm{MIC}[\mu \mathrm{M}]$} & \multirow{2}{*}{$\mathrm{LD}_{50}[\mu \mathrm{M}]$} \\
\hline & & & & & & SA & MRSA SA 630 & MRSA 3202 & MM & MK & \\
\hline 1 & $\mathrm{Cl}$ & - & 5.03 & - & - & 215 & 860 & 860 & 107 & 107 & $>30$ \\
\hline 3 & $\mathrm{Cl}$ & Et & 3.94 & 47.29 & -0.11 & 21.6 & 43.3 & 43.3 & 21.6 & 21.6 & $>30$ \\
\hline 4 & $\mathrm{Cl}$ & Pr & 4.41 & 63.80 & -0.12 & 83.5 & 83.5 & 83.5 & 41.7 & 36.5 & $>30$ \\
\hline 5 & $\mathrm{Cl}$ & $\mathrm{Bu}$ & 4.71 & 80.31 & -0.25 & 645 & 645 & 645 & 80.6 & 80.6 & - \\
\hline 6 & $\mathrm{Cl}$ & Pen & 5.47 & 96.81 & -0.23 & 623 & 623 & 623 & 77.8 & 77.8 & - \\
\hline 7 & $\mathrm{Cl}$ & Hex & 6.03 & 113.32 & -0.25 & 602 & 602 & 602 & 75.3 & 75.3 & - \\
\hline 8 & $\mathrm{Cl}$ & Hep & 6.67 & 129.83 & -0.23 & 583 & 583 & 583 & 72.9 & 72.9 & - \\
\hline 9 & $\mathrm{Cl}$ & Oct & 7.19 & 146.33 & -0.23 & 565 & 565 & 565 & 70.6 & 70.6 & - \\
\hline 10 & $\mathrm{Cl}$ & i-Pr & 4.20 & 64.18 & -0.19 & 83.5 & 167 & 167 & 41.7 & 41.7 & $>30$ \\
\hline 11 & $\mathrm{Cl}$ & c-Pent & 4.60 & 84.10 & -0.20 & 313 & 313 & 626 & 78.2 & 78.2 & - \\
\hline 12 & $\mathrm{Cl}$ & c-Hex & 5.03 & 100.87 & -0.15 & 303 & 605 & 303 & 75.6 & 75.6 & - \\
\hline 13 & $\mathrm{Cl}$ & c-Hep & 5.46 & 117.56 & -0.14 & 146 & 586 & 586 & 73.2 & 73.2 & - \\
\hline 14 & $\mathrm{Cl}$ & PhEt & 5.19 & 108.00 & 0.08 & 288 & 575 & 575 & 71.9 & 71.9 & - \\
\hline 15 & $\mathrm{Cl}$ & $\mathrm{PhBu}$ & 5.75 & 141.01 & -0.21 & 271 & 541 & 541 & 67.6 & 67.6 & - \\
\hline 2 & $\mathrm{NO}_{2}$ & - & 4.45 & - & - & 26 & 104 & 52 & 104 & 51.9 & $>30$ \\
\hline 16 & $\mathrm{NO}_{2}$ & Et & 3.58 & 47.29 & -0.11 & 5.27 & 42.1 & 42.1 & 21.0 & 21.0 & $>30$ \\
\hline 17 & $\mathrm{NO}_{2}$ & Pr & 3.96 & 63.80 & -0.12 & 10.1 & 81.3 & 81.3 & 40.6 & 40.6 & $>30$ \\
\hline 18 & $\mathrm{NO}_{2}$ & $\mathrm{Bu}$ & 4.32 & 80.31 & -0.25 & 628 & 628 & 628 & 78.5 & 78.5 & - \\
\hline 19 & $\mathrm{NO}_{2}$ & Pen & 5.15 & 96.81 & -0.23 & 607 & 607 & 607 & 75.9 & 75.9 & - \\
\hline 20 & $\mathrm{NO}_{2}$ & Hex & 5.71 & 113.32 & -0.25 & 587 & 587 & 587 & 73.4 & 73.4 & - \\
\hline 21 & $\mathrm{NO}_{2}$ & Hep & 6.81 & 129.83 & -0.23 & 569 & 569 & 569 & 71.1 & 71.1 & - \\
\hline 22 & $\mathrm{NO}_{2}$ & Oct & 7.22 & 146.33 & -0.23 & 552 & 552 & 552 & 69.0 & 69.0 & - \\
\hline 23 & $\mathrm{NO}_{2}$ & i-Pr & 3.80 & 64.18 & -0.19 & 40.6 & 162 & 162 & 40.6 & 40.6 & $>30$ \\
\hline 24 & $\mathrm{NO}_{2}$ & c-Pent & 4.21 & 84.10 & -0.20 & 153 & 610 & 610 & 76.2 & 76.2 & - \\
\hline 25 & $\mathrm{NO}_{2}$ & c-Hex & 4.60 & 100.87 & -0.15 & 74 & 591 & 591 & 73.8 & 73.8 & - \\
\hline 26 & $\mathrm{NO}_{2}$ & c-Hep & 5.05 & 117.56 & -0.14 & 72 & 572 & 572 & 71.5 & 71.5 & - \\
\hline 27 & $\mathrm{NO}_{2}$ & PhEt & 4.67 & 108.00 & 0.08 & 281 & 562 & 562 & 70.2 & 70.2 & - \\
\hline 28 & $\mathrm{NO}_{2}$ & $\mathrm{PhBu}$ & 5.55 & 141.01 & -0.21 & 132 & 529 & 529 & 66.1 & 66.1 & - \\
\hline APC & - & & - & - & - & 5.72 & 45.8 & 45.8 & - & - & - \\
\hline INH & - & & - & - & - & - & - & - & 467 & 29.2 & - \\
\hline
\end{tabular}

\subsection{In Vitro Antibacterial Susceptibility Testing}

The in vitro antibacterial activity of the discussed compounds was evaluated against two clinical isolates of methicillin-resistant Staphylococcus aureus (MRSA) and S. aureus ATCC 29213 as a reference 
and quality control strain. All the compounds showed only moderate or negligible activity, except ethylcarbamates $3\left(\mathrm{R}^{1}=\mathrm{Cl}\right)$ and $\mathbf{1 6}\left(\mathrm{R}^{1}=\mathrm{NO}_{2}\right)$. The activity of both ethylcarbamates 3 and $\mathbf{1 6}$ was comparable with that of the standard ampicillin; furthermore, the effect of compound $\mathbf{1 6}$ against S. aureus was ca. 4-fold higher in comparison with that of the chloro derivative 3 . In addition, nitrated propylcarbamate $\mathbf{1 7}$ showed ca. 8-fold higher activity than the corresponding chlorinated compound $\mathbf{4}$, and nitro-anilide $\mathbf{2}$ had ca. 8-fold higher effectivity against $S$. aureus than chloro-anilide $\mathbf{1}$. The observation that anilides substituted by the nitro moiety on the anilide ring showed higher potency only against $S$. aureus and not against MRSA strains in comparison with chlorine substituted derivatives was also described by Pauk et al. [37]. It can be supposed that nitro derivatives may interact by hydrogen bonding with specific biological structures in S. aureus (that are not present in MRSA strains). These interactions are limited only for spatially small molecules, such as anilide and ethyl-, propyl-, and isopropylcarbamate, while carbamates with bulkier (long or branched) tails are not capable of these interactions. This fact was also confirmed by Zadrazilova et al., where short ethylcarbamates demonstrated higher bacteriostatic activity against various Staphylococcus strains than longer $\left(C_{9}-C_{12}\right)$ alkylcarbamates [16]. Due to the moderate activity of the rest of the compounds, no thorough structure-activity relationships could be established. Nevertheless, in general, it can be stated that the activity is influenced by similar factors/parameters as those discussed below.

\subsection{In Vitro Antimycobacterial Evaluation}

The evaluation of the in vitro antimycobacterial activity of the compounds was performed against Mycobacterium marinum CAMP 5644 (MM) and M. kansasii DSM 44162 (MK), see Table 1. To lower risks and make manipulation in the laboratory easier, surrogate model pathogens for M. tuberculosis can be used in laboratory studies. Mycobacterium marinum is very closely related to $M$. tuberculosis and is the cause of tuberculosis-like infections in poikilothermic organisms, especially frogs and fish. M. marinum is a good model for study especially because of the lower risk for laboratory workers, genetic relatedness, and pathology similar to human tuberculosis [38]. However, because of $M$. tuberculosis, the pathogenic role of nontuberculous mycobacteria (NTM) in humans was underestimated for a long time [39]. M. kansasii, the most virulent of the NTM, causes nontuberculous mycobacterial lung infections that are very common nowadays and can be indistinguishable from tuberculosis [40]. Therefore, additionally M. kansasii was chosen as a model species for screening of prospective antimycobacterial drugs to control mycobacterial diseases. The activity of the compounds was expressed as the minimum inhibitory concentration (MIC) that is defined for mycobacteria as a $90 \%$ or greater $\left(\mathrm{IC}_{90}\right)$ reduction of growth in comparison with the control [41].

It can be stated that the potency of almost all discussed compounds is the same against both mycobacterial strains (see Table 1). Similarly, as mentioned above, ethylcarbamates $3\left(\mathrm{R}^{1}=\mathrm{Cl}\right)$ and $16\left(\mathrm{R}^{1}=\mathrm{NO}_{2}\right)$ showed the highest antimycobacterial activity $(\mathrm{MICs}=21 \mu \mathrm{M})$. In addition, propylcarbamates $4\left(\mathrm{R}^{1}=\mathrm{Cl}\right)$ and $\mathbf{1 7}\left(\mathrm{R}^{2}=\mathrm{NO}_{2}\right)$ expressed substantial activity (MICs ca. $\left.40 \mu \mathrm{M}\right)$. The dependences of the antimycobacterial activity expressed as $\log (1 / \mathrm{MIC})$ on the lipophilicity $(\log P)$ of the compounds as well as on the bulkiness/molar volume ( $\left.\mathrm{MV}\left[\mathrm{cm}^{3}\right]\right)$ of individual alkyl/cycloalkyl/arylalkyl chains are illustrated in Figure 1A,B. Practically the same structure-activity relationships can be found for both series; therefore they are illustrated only for $M$. kansasii. The activity rapidly decreases with lipophilicity and with substituent bulkiness, increasing up to $\log P$ ca. 4.4 or MV ca. $80 \mathrm{~cm}^{3}$ ( $\mathrm{R}^{2}=$ butyl or cyclopentyl), respectively, and then remains practically constant (or increases insignificantly) with increasing lipophilicity/bulkiness (see Figure 1A,B). For example, correlation factor $\mathrm{r}=0.9919, \mathrm{n}=10$ (compounds $\mathbf{3}-\mathbf{5}, \mathbf{1 0}, \mathbf{1 1}, \mathbf{1 6}-\mathbf{1 8}, \mathbf{2 3}, \mathbf{2 4}$ ) of the dependence of activity on the bulkiness of the $R^{2}$ substituent can be calculated. It seems that the activity is also secondarily influenced by the electronic properties of $R^{2}$ substituents expressed as electronic constants $\sigma^{*}$, because it can be stated that the more the $\sigma^{*}$ values approximate -0.11 (i.e., the less electron donor properties are), the higher the activity is (see Figure 2). 

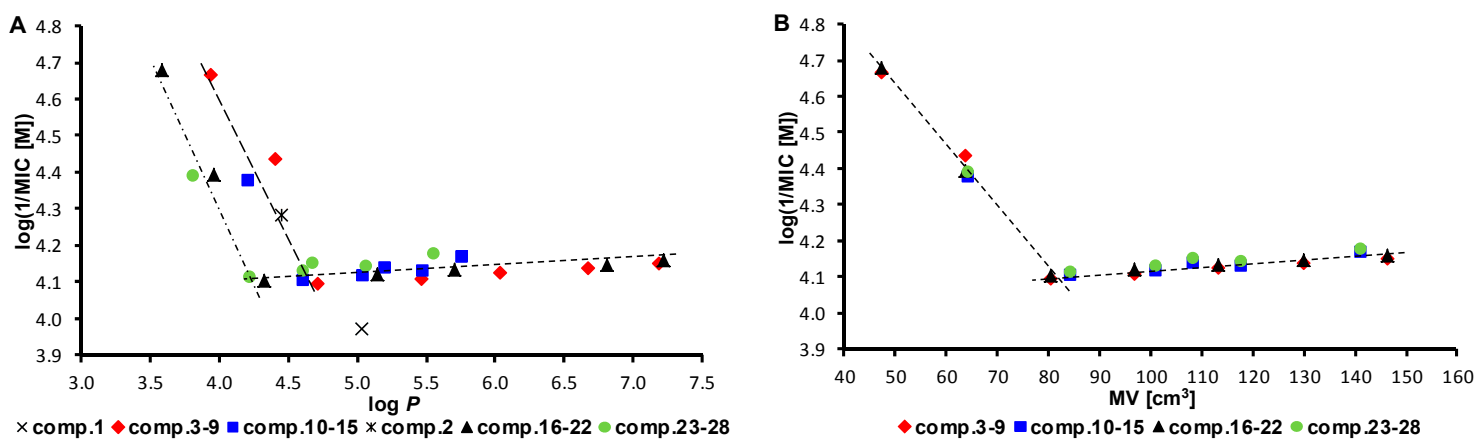

Figure 1. Dependence of the in vitro antimycobacterial activity against $M$. kansasii DSM $44162 \log$ (1/MIC [M]) of the tested compounds on lipophilicity, expressed as $\log P(\mathbf{A})$ and bulkiness/molar volume (MV $\left.\left[\mathrm{cm}^{3}\right]\right)$ of individual $\mathrm{R}^{2}$ substituents $(\mathbf{B})$.

$\sigma^{*}=$\begin{tabular}{llllll}
$\mathrm{Bu}(\mathbf{5} / \mathbf{1 8})$ & $\mathrm{cPent}(\mathbf{1 1 / 2 4})$ & $\mathrm{cHex}(\mathbf{1 2} / \mathbf{2 5})$ & $\mathrm{cHep} \mathrm{(13/26)}$ & $\operatorname{Pr}(\mathbf{4} / \mathbf{1 7})$ & $\mathrm{Et} \mathrm{(3/16)}$ \\
\hline-0.25 & -0.20 & -0.15 & -0.14 & -0.12 & -0.11
\end{tabular}

Figure 2. Increase of the general antimicrobial activity owing to the $\mathrm{R}^{2}$ substituent in dependence on the electronic properties are expressed as electronic constants $\sigma^{*}$.

In the previous studies [24,42], the most potent carbamates were substituted by a longer tail, which is connected with their surface activity. In this case, no dependence of antibacterial/antimycobacterial effects on surface activity was observed. As ethylcarbamates showed the highest activity in the discussed screening and propyl- and isopropyl-carbamates showed medium activity, it seems that steric requirements (spatially small molecules) play a significant role for a good biological effect. Similar facts were recently described, for example, by Kratky et al., where carbamates with spatially bulky tails expressed significantly lower activity than short-tail carbamates [43]. On the other hand, the blocking of the phenolic moiety by the carbamate group significantly increased the antimicrobial effect of these compounds. The mode of action (targets) of these compounds is questionable; however, due to the structural similarity with salicylanilides, interactions with vital enzymes, energy metabolism, as well as disturbing of the membrane architecture of prokaryotic cells may be supposed $[10,11,13-17,32,33,36,44]$.

\subsection{In Vitro Cytotoxicity Assay}

The preliminary in vitro screening of the cytotoxicity of the compounds was performed using the human monocytic leukemia THP-1 cell line. The cytotoxicity was evaluated as the $\mathrm{LD}_{50}$ value ( $\mathrm{LD}_{50}$ - lethal dose to $50 \%$ of the cell population), see Table 1 . A compound is considered cytotoxic when it demonstrates a toxic effect on cells at concentrations up to $10 \mu \mathrm{M}$ [45], and the highest tested concentration that was used for the toxicity assay was 3-fold this value. Treatment with $30 \mu \mathrm{M}$ compounds did not lead to lethal effects on the THP-1 cells. Based on these observations, it can be concluded that the most potent compounds $\mathbf{3}$ and $\mathbf{1 6}$ can be considered as promising agents for subsequent design of novel antibacterial and antimycobacterial agents.

\section{Experimental Section}

\subsection{General Information}

All reagents were purchased from Aldrich (Sigma-Aldrich, St. Louis, MO, USA), and Alfa (Alfa-Aesar, Ward Hill, MA, USA). TLC experiments were performed on alumina-backed silica gel 60 F254 plates (Merck, Darmstadt, Germany). The plates were illuminated under UV light (254 nm) and evaluated in iodine vapour. The melting points were determined on a Kofler hot-plate apparatus HMK (Franz Kustner Nacht KG, Dresden, Germany) and are uncorrected. Infrared (IR) spectra were recorded 
on a Smart MIRacle ${ }^{\mathrm{TM}}$ ATR ZnSe for Nicolet ${ }^{\mathrm{TM}}$ Impact 410 FT-IR spectrometer (Thermo Scientific, West Palm Beach, FL, USA). The spectra were obtained by the accumulation of 256 scans with a $2 \mathrm{~cm}^{-1}$ resolution in the region of $4000-650 \mathrm{~cm}^{-1}$. All ${ }^{1} \mathrm{H}$ - and ${ }^{13} \mathrm{C}-\mathrm{NMR}$ spectra were recorded on a JEOL ECZR $400 \mathrm{MHz}$ NMR spectrometer $\left(400 \mathrm{MHz}\right.$ for ${ }^{1} \mathrm{H}$ and $100 \mathrm{MHz}$ for ${ }^{13} \mathrm{C}$, JEOL, Tokyo, Japan) in DMSO- $d_{6} \cdot{ }^{1} \mathrm{H}$ and ${ }^{13} \mathrm{C}$ chemical shifts $(\delta)$ are reported in ppm. High-resolution mass spectra were measured using a high-performance liquid chromatograph Dionex UltiMate ${ }^{\circledR} 3000$ (Thermo Scientific) coupled with a LTQ Orbitrap XL ${ }^{\mathrm{TM}}$ Hybrid Ion Trap-Orbitrap Fourier Transform Mass Spectrometer (Thermo Scientific) with injection into HESI II in the positive mode. The lipophilicity $(\log P)$ of the final compounds, the surface tension, and the molar volume of $\mathrm{R}$ substituents were predicted using ACD/Percepta ver. 2012 (Advanced Chemistry Development, Inc., Toronto, ON, Canada).

\subsection{Synthesis}

General Procedure for Synthesis of Carbamates 3-28

The synthetic pathway and characterization of $N$-(2-chlorophenyl)-2-hydroxynaphthalene1-carboxamide (1) and $N$-(2-nitrophenyl)-2-hydroxynaphthalene-1-carboxamide (2) were described recently by Gonec et al. [30]. Anilides 1 and $2(1.0 \mathrm{mmol})$ and triethylamine $(1.1 \mathrm{mmol})$ were dissolved in dry acetonitrile $(10 \mathrm{~mL})$. The solution of the appropriate alkyl isocyanate $(1.2 \mathrm{mmol})$ in acetonitrile $(5 \mathrm{~mL})$ was added in four portions within $2 \mathrm{~h}$, and the reacting mixture was stirred for $24 \mathrm{~h}$ at ambient temperature. The solvent was evaporated under reduced pressure, and the solid residue was washed with methanol and ethyl acetate to give pure product. All the studied compounds are presented in Table 1.

1-[(2-Chlorophenyl)carbamoyl]naphthalen-2-yl ethylcarbamate (3). Yield 33\%; Mp 137-139 ${ }^{\circ} \mathrm{C} ; \mathrm{IR}\left(\mathrm{cm}^{-1}\right)$ : 3264, 3214, 1718, 1675, 1540, 1523, 1510, 1481, 1435, 1300, 1256, 1229, 1006, 826, 741, 723, 688, 667; ${ }^{1} \mathrm{H}-\mathrm{NMR}$ (DMSO- $\left.d_{6}\right) \delta: 10.14(\mathrm{~s}, 1 \mathrm{H}), 7.99-8.06(\mathrm{~m}, 3 \mathrm{H}), 7.88(\mathrm{t}, J=5.5 \mathrm{~Hz}, 1 \mathrm{H}), 7.82(\mathrm{dd}, J=8.2 \mathrm{~Hz}$, $1.3 \mathrm{~Hz}, 1 \mathrm{H}), 7.64(\mathrm{ddd}, J=8.2 \mathrm{~Hz}, 6.9 \mathrm{~Hz}, 1.0 \mathrm{~Hz}, 1 \mathrm{H}), 7.55-7.59(\mathrm{~m}, 2 \mathrm{H}), 7.43(\mathrm{td}, J=7.7 \mathrm{~Hz}, 1.6 \mathrm{~Hz}$, $1 \mathrm{H}), 7.42(\mathrm{~d}, J=9.0 \mathrm{~Hz}, 1 \mathrm{H}), 7.30(\mathrm{td}, J=7.8 \mathrm{~Hz}, 1.3 \mathrm{~Hz}, 1 \mathrm{H}), 3.08-3.15(\mathrm{~m}, 2 \mathrm{H}), 1.08(\mathrm{t}, J=7.3 \mathrm{~Hz}, 3 \mathrm{H})$; ${ }^{13}$ C-NMR (DMSO- $d_{6}$ ), $\delta: 164.33,153.97,142.20,134.65,130.54,130.31,129.77,129.60,128.40,128.04$, $127.58,127.30,127.43,127.28,126.60,125.78,124.67,122.62,35.42,14.83$; HR-MS: for $\mathrm{C}_{20} \mathrm{H}_{16} \mathrm{O}_{3} \mathrm{~N}_{2} \mathrm{Cl}$ $[\mathrm{M}+\mathrm{H}]^{+}$calculated $367.08440 \mathrm{~m} / \mathrm{z}$, found $367.08545 \mathrm{~m} / \mathrm{z}$.

1-[(2-Chlorophenyl)carbamoyl]naphthalen-2-yl propylcarbamate (4). Yield 26\%; Mp 132-134 ${ }^{\circ} \mathrm{C}$; IR $\left(\mathrm{cm}^{-1}\right)$ : 3259, 3224, 1716, 1659, 1546, 1526, 1510, 1484, 1441, 1298, 1259, 1232, 1060, 991, 809, 741, 694; ${ }^{1} \mathrm{H}-\mathrm{NMR}$ (DMSO- $\left.d_{6}\right) \delta: 10.10(\mathrm{~s}, 1 \mathrm{H}), 7.99-8.05(\mathrm{~m}, 3 \mathrm{H}), 7.89(\mathrm{t}, J=5.7 \mathrm{~Hz}, 1 \mathrm{H}), 7.83(\mathrm{dd}, J=8.2 \mathrm{~Hz}, 1.3 \mathrm{~Hz}, 1 \mathrm{H})$, $7.64(\mathrm{ddd}, J=8.2 \mathrm{~Hz}, 6.9 \mathrm{~Hz}, 1.0 \mathrm{~Hz}, 1 \mathrm{H}), 7.55-7.59(\mathrm{~m}, 2 \mathrm{H}), 7.42(\mathrm{td}, J=7.7 \mathrm{~Hz}, 1.6 \mathrm{~Hz}, 1 \mathrm{H}), 7.41(\mathrm{~d}$, $J=9.0 \mathrm{~Hz}, 1 \mathrm{H}), 7.30(\mathrm{td}, J=7.8 \mathrm{~Hz}, 1.3 \mathrm{~Hz}, 1 \mathrm{H}), 3.04(\mathrm{q}, J=6.4 \mathrm{~Hz}, 2 \mathrm{H}), 1.47(\mathrm{sx}, J=7.2 \mathrm{~Hz}, 2 \mathrm{H}), 0.86(\mathrm{t}$, $J=7.6 \mathrm{~Hz}, 3 \mathrm{H}$ ); ${ }^{13} \mathrm{C}-\mathrm{NMR}\left(\mathrm{DMSO}-d_{6}\right), \delta: 164.33,154.20,145.23,134.67,130.56,130.31,129.81,129.59$, $128.33,128.04,127.48,127.42,127.30,127.28,126.60,125.78,124.67,122.62,42.35,22.45,11.17$; HR-MS: for $\mathrm{C}_{21} \mathrm{H}_{18} \mathrm{O}_{3} \mathrm{~N}_{2} \mathrm{Cl}[\mathrm{M}+\mathrm{H}]^{+}$calculated $381.10005 \mathrm{~m} / \mathrm{z}$, found $381.10123 \mathrm{~m} / \mathrm{z}$.

1-[(2-Chlorophenyl)carbamoyl]naphthalen-2-yl butylcarbamate (5). Yield 55\%; Mp 156-159 ${ }^{\circ} \mathrm{C} ; \mathrm{IR}\left(\mathrm{cm}^{-1}\right)$ : 3258, 3228, 1724, 1665, 1553, 1526, 1506, 1479, 1439, 1232, 1007, 818, 751; ${ }^{1} \mathrm{H}-\mathrm{NMR}$ (DMSO-d 6 ) $\delta: 10.08$ $(\mathrm{s}, 1 \mathrm{H}), 7.99-8.05(\mathrm{~m}, 3 \mathrm{H}), 7.88(\mathrm{t}, J=5.5 \mathrm{~Hz}, 1 \mathrm{H}), 7.85(\mathrm{dd}, J=8.2 \mathrm{~Hz}, 1.3 \mathrm{~Hz}, 1 \mathrm{H}), 7.64(\mathrm{ddd}, J=8.2 \mathrm{~Hz}$, $6.9 \mathrm{~Hz}, 1.0 \mathrm{~Hz}, 1 \mathrm{H}), 7.55-7.59(\mathrm{~m}, 2 \mathrm{H}), 7.42(\mathrm{td}, J=7.7 \mathrm{~Hz}, 1.6 \mathrm{~Hz}, 1 \mathrm{H}), 7.41(\mathrm{~d}, J=9.0 \mathrm{~Hz}, 1 \mathrm{H}), 7.30$ $(\mathrm{td}, J=7.8 \mathrm{~Hz}, 1.3 \mathrm{~Hz}, 1 \mathrm{H}), 3.08(\mathrm{q}, J=6.4 \mathrm{~Hz}, 2 \mathrm{H}), 1.44(\mathrm{qi}, J=7.2 \mathrm{~Hz}, 2 \mathrm{H}), 1.28(\mathrm{sx}, J=7.3 \mathrm{~Hz}, 2 \mathrm{H})$, $0.85(\mathrm{t}, J=7.3 \mathrm{~Hz}, 3 \mathrm{H}) ;{ }^{13} \mathrm{C}-\mathrm{NMR}$ (DMSO- $\left.d_{6}\right), \delta: 164.31,154.19,145.23,134.67,130.57,130.31,129.84$, 129.60, 128.20, 128.05, 127.41, 127.32, 127.31, 127.22, 126.59, 125.79, 124.65, 122.60, 40.26, 31.32, 19.37, 13.63; HR-MS: for $\mathrm{C}_{22} \mathrm{H}_{20} \mathrm{O}_{3} \mathrm{~N}_{2} \mathrm{Cl}[\mathrm{M}+\mathrm{H}]^{+}$calculated $395.11570 \mathrm{~m} / \mathrm{z}$, found $395.11639 \mathrm{~m} / \mathrm{z}$.

1-[(2-Chlorophenyl)carbamoyl]naphthalen-2-yl pentylcarbamate (6). Yield $36 \% ; \mathrm{Mp} 137-138^{\circ} \mathrm{C} ; \mathrm{IR}\left(\mathrm{cm}^{-1}\right)$ : $3227,3215,1724,1669,1550,1521,1508,1480,1434,1233,1037,997,910,817,746,686 ;{ }^{1} \mathrm{H}-\mathrm{NMR}$ $\left(\right.$ DMSO- $\left.d_{6}\right) \delta: 10.08(\mathrm{~s}, 1 \mathrm{H}), 7.99-8.05(\mathrm{~m}, 3 \mathrm{H}), 7.88(\mathrm{t}, J=5.5 \mathrm{~Hz}, 1 \mathrm{H}), 7.85(\mathrm{dd}, J=8.2 \mathrm{~Hz}, 1.3 \mathrm{~Hz}, 1 \mathrm{H})$, 
$7.64(\mathrm{ddd}, J=8.2 \mathrm{~Hz}, 6.9 \mathrm{~Hz}, 1.0 \mathrm{~Hz}, 1 \mathrm{H}), 7.55-7.59(\mathrm{~m}, 2 \mathrm{H}), 7.39-7.44(\mathrm{~m}, 2 \mathrm{H}), 7.30(\mathrm{td}, J=7.8 \mathrm{~Hz}$, $1.3 \mathrm{~Hz}, 1 \mathrm{H}), 3.07(\mathrm{q}, J=6.7 \mathrm{~Hz}, 2 \mathrm{H}), 1.45(\mathrm{qi}, J=7.0 \mathrm{~Hz}, 2 \mathrm{H}), 1.24-1.28(\mathrm{~m}, 4 \mathrm{H}), 0.84(\mathrm{t}, J=7.0 \mathrm{~Hz}, 3 \mathrm{H})$; ${ }^{13}$ C-NMR (DMSO- $d_{6}$ ) $, \delta: 164.39,154.24,145.26,134.68,130.62,130.36,129.90,129.65,128.27,128.10$, 127.46, 127.40, 127.37, 127.31, 126.64, 125.87, 124.70, 122.65, 40.59, 28.91, 28.42, 21.87, 13.92; HR-MS: for $\mathrm{C}_{23} \mathrm{H}_{22} \mathrm{O}_{3} \mathrm{~N}_{2} \mathrm{Cl}[\mathrm{M}+\mathrm{H}]^{+}$calculated $409.13135 \mathrm{~m} / \mathrm{z}$, found $409.13303 \mathrm{~m} / \mathrm{z}$.

1-[(2-Chlorophenyl)carbamoyl]naphthalen-2-yl hexylcarbamate (7). Yield 50\%; Mp 103-106 ${ }^{\circ} \mathrm{C} ; \mathrm{IR}\left(\mathrm{cm}^{-1}\right)$ : 2954, 2924, 1725, 1673, 1587, 1525, 1516, 1463, 1440, 1301, 1241, 1210, 1037, 995, 813, 756, 747, 684; ${ }^{1} \mathrm{H}-\mathrm{NMR}\left(\mathrm{DMSO}-d_{6}\right) \delta: 10.08(\mathrm{~s}, 1 \mathrm{H}), 7.99-8.05(\mathrm{~m}, 3 \mathrm{H}), 7.88(\mathrm{t}, J=5.5 \mathrm{~Hz}, 1 \mathrm{H}), 7.85(\mathrm{dd}, J=8.2 \mathrm{~Hz}$, $1.3 \mathrm{~Hz}, 1 \mathrm{H}), 7.64(\mathrm{ddd}, J=8.2 \mathrm{~Hz}, 6.9 \mathrm{~Hz}, 1.0 \mathrm{~Hz}, 1 \mathrm{H}), 7.55-7.59(\mathrm{~m}, 2 \mathrm{H}), 7.39-7.44(\mathrm{~m}, 2 \mathrm{H}), 7.30(\mathrm{td}$, $J=7.8 \mathrm{~Hz}, 1.3 \mathrm{~Hz}, 1 \mathrm{H}), 3.07(\mathrm{q}, J=6.4 \mathrm{~Hz}, 2 \mathrm{H}), 1.45(\mathrm{qi}, J=7.0 \mathrm{~Hz}, 2 \mathrm{H}), 1.20-1.31(\mathrm{~m}, 6 \mathrm{H}), 0.85(\mathrm{t}$, $J=6.9 \mathrm{~Hz}, 3 \mathrm{H}$ ); ${ }^{13} \mathrm{C}-\mathrm{NMR}$ (DMSO- $d_{6}$ ), $\delta: 164.39,154.26,145.26,134.70,130.63,130.37,129.93,129.66$, $128.25,128.13,127.46,127.39,127.36,127.30,126.66,125.88,124.71,122.65,40.64,31.03,29.21,25.92$, 22.07, 13.96; HR-MS: for $\mathrm{C}_{24} \mathrm{H}_{24} \mathrm{O}_{3} \mathrm{~N}_{2} \mathrm{Cl}[\mathrm{M}+\mathrm{H}]^{+}$calculated $423.14700 \mathrm{~m} / \mathrm{z}$, found $423.14767 \mathrm{~m} / \mathrm{z}$.

1-[(2-Chlorophenyl)carbamoyl]naphthalen-2-yl heptylcarbamate (8). Yield 66\%; Mp 89-90 ${ }^{\circ} \mathrm{C}$; IR $\left(\mathrm{cm}^{-1}\right)$ : 3279, 3227, 2956, 2933, 2923, 1720, 1662, 1538, 1520, 1479, 1463, 1438, 1296, 1266, 1253, 1234, 1192, 1060, 986, 911, 816, 750; ${ }^{1} \mathrm{H}-\mathrm{NMR}\left(\mathrm{DMSO}-d_{6}\right) \delta: 10.08(\mathrm{~s}, 1 \mathrm{H}), 7.99-8.05(\mathrm{~m}, 3 \mathrm{H}), 7.88(\mathrm{t}, J=5.5 \mathrm{~Hz}, 1 \mathrm{H}), 7.86$ $(\mathrm{dd}, J=8.2 \mathrm{~Hz}, 1.3 \mathrm{~Hz}, 1 \mathrm{H}), 7.64(\mathrm{ddd}, J=8.2 \mathrm{~Hz}, 6.9 \mathrm{~Hz}, 1.0 \mathrm{~Hz}, 1 \mathrm{H}), 7.55-7.59(\mathrm{~m}, 2 \mathrm{H}), 7.39-7.44$ $(\mathrm{m}, 2 \mathrm{H}), 7.30(\mathrm{td}, J=7.8 \mathrm{~Hz}, 1.3 \mathrm{~Hz}, 1 \mathrm{H}), 3.07(\mathrm{q}, J=6.4 \mathrm{~Hz}, 2 \mathrm{H}), 1.45(\mathrm{qi}, J=7.0 \mathrm{~Hz}, 2 \mathrm{H}), 1.20-1.29$ $(\mathrm{m}, 8 \mathrm{H}), 0.85(\mathrm{t}, J=6.9 \mathrm{~Hz}, 3 \mathrm{H}) ;{ }^{13} \mathrm{C}-\mathrm{NMR}\left(\mathrm{DMSO}-d_{6}\right), \delta: 164.42,154.29,145.28,134.71,130.65,130.39$, 129.96, 129.68, 128.27, 128.14, 127.48, 127.41, 127.39, 127.31, 126.67, 125.90, 124.73, 122.67, 40.65, 31.26, 29.26, 28.48, 26.22, 22.11, 14.02; HR-MS: for $\mathrm{C}_{25} \mathrm{H}_{26} \mathrm{O}_{3} \mathrm{~N}_{2} \mathrm{Cl}[\mathrm{M}+\mathrm{H}]^{+}$calculated $437.16265 \mathrm{~m} / \mathrm{z}$, found $437.16431 \mathrm{~m} / \mathrm{z}$.

1-[(2-Chlorophenyl)carbamoyl]naphthalen-2-yl octylcarbamate (9). Yield 52\%; Mp 115-116 ${ }^{\circ} \mathrm{C} ; \mathrm{IR}\left(\mathrm{cm}^{-1}\right)$ : 3297, 3286, 2924, 2851, 1724, 1673, 1584, 1548, 1540, 1509, 1467, 1441, 1434, 1299, 1246, 1215, 1160, 993, 827, 756, 747, 734, 677; ${ }^{1} \mathrm{H}-\mathrm{NMR}$ (DMSO- $\left.d_{6}\right) \delta: 10.08(\mathrm{~s}, 1 \mathrm{H}), 7.99-8.05(\mathrm{~m}, 3 \mathrm{H}), 7.88(\mathrm{t}, J=5.5 \mathrm{~Hz}, 1 \mathrm{H})$, $7.85(\mathrm{dd}, J=8.2 \mathrm{~Hz}, 1.3 \mathrm{~Hz}, 1 \mathrm{H}), 7.64(\mathrm{ddd}, J=8.2 \mathrm{~Hz}, 6.9 \mathrm{~Hz}, 1.0 \mathrm{~Hz}, 1 \mathrm{H}), 7.54-7.59(\mathrm{~m}, 2 \mathrm{H}), 7.39-7.43$ $(\mathrm{m}, 2 \mathrm{H}), 7.30(\mathrm{td}, J=7.8 \mathrm{~Hz}, 1.3 \mathrm{~Hz}, 1 \mathrm{H}), 3.07(\mathrm{q}, J=6.4 \mathrm{~Hz}, 2 \mathrm{H}), 1.45(\mathrm{qi}, J=7.0 \mathrm{~Hz}, 2 \mathrm{H}), 1.21-1.30(\mathrm{~m}$, $10 \mathrm{H}), 0.86(\mathrm{t}, J=6.9 \mathrm{~Hz}, 3 \mathrm{H}) ;{ }^{13} \mathrm{C}-\mathrm{NMR}$ (DMSO- $\left.d_{6}\right), \delta: 164.33,154.19,145.23,134.68,130.57,130.33$, $129.87,129.60,128.22,128.07,127.40,127.35,127.33,127.22,126.61,125.81,124.67,122.60,40.59,31.25$, 29.20, 28.73, 28.64, 26.21, 22.10, 13.96; HR-MS: for $\mathrm{C}_{26} \mathrm{H}_{28} \mathrm{O}_{3} \mathrm{~N}_{2} \mathrm{Cl}[\mathrm{M}+\mathrm{H}]^{+}$calculated $451.17830 \mathrm{~m} / z$, found $451.18018 \mathrm{~m} / \mathrm{z}$.

1-[(2-Chlorophenyl)carbamoyl]naphthalen-2-yl isoproylcarbamate (10). Yield 39\%; Mp 167-169 ${ }^{\circ} \mathrm{C}$; IR $\left(\mathrm{cm}^{-1}\right)$ : 3249, 3216, 1971, 1716, 1668, 1581, 1544, 1530, 1510, 1481, 1462, 1439, 1324, 1300, 1256, 1234, 1066, 1022, 962, 910, 820, 742, 697; ${ }^{1} \mathrm{H}-\mathrm{NMR}\left(\mathrm{DMSO}_{-} \mathrm{d}_{6}\right) \delta: 10.09(\mathrm{~s}, 1 \mathrm{H}), 7.99-8.06(\mathrm{~m}, 3 \mathrm{H}), 7.86(\mathrm{t}, J=5.5 \mathrm{~Hz}, 1 \mathrm{H})$, $7.84(\mathrm{dd}, J=8.2 \mathrm{~Hz}, 1.3 \mathrm{~Hz}, 1 \mathrm{H}), 7.64(\mathrm{ddd}, J=8.2 \mathrm{~Hz}, 6.9 \mathrm{~Hz}, 1.0 \mathrm{~Hz}, 1 \mathrm{H}), 7.56-7.59(\mathrm{~m}, 2 \mathrm{H}), 7.43(\mathrm{td}$, $J=7.7 \mathrm{~Hz}, 1.6 \mathrm{~Hz}, 1 \mathrm{H}), 7.41(\mathrm{~d}, J=9.0 \mathrm{~Hz}, 1 \mathrm{H}), 7.30(\mathrm{td}, J=7.8 \mathrm{~Hz}, 1.3 \mathrm{~Hz}, 1 \mathrm{H}), 3.69(\mathrm{sx}, J=6.6 \mathrm{~Hz}, 1 \mathrm{H})$, $1.12(\mathrm{~d}, J=6.6 \mathrm{~Hz}, 6 \mathrm{H}) ;{ }^{13} \mathrm{C}-\mathrm{NMR}$ (DMSO- $\left.d_{6}\right), \delta: 164.42,153.41,145.28,134.70,130.60,130.37,129.90$, 129.65, 128.34, 128.10, 127.49, 127.48, 127.36, 127.35, 126.67, 125.85, 124.70, 122.71, 42.91, 22.40; HR-MS: for $\mathrm{C}_{21} \mathrm{H}_{18} \mathrm{O}_{3} \mathrm{~N}_{2} \mathrm{Cl}[\mathrm{M}+\mathrm{H}]^{+}$calculated $381.10005 \mathrm{~m} / \mathrm{z}$, found $381.10123 \mathrm{~m} / \mathrm{z}$.

1-[(2-Chlorophenyl)carbamoyl]naphthalen-2-yl cyclopentylcarbamate (11). Yield 60\%; Mp 135-137 ${ }^{\circ} \mathrm{C}$; IR $\left(\mathrm{cm}^{-1}\right)$ : 3224, 2951, 1713, 1659, 1544, 1525, 1509, 1485, 1467, 1440, 1290, 1256, 1233, 1151, 1060, $1052,1013,911,815,784,740,688,680 ;{ }^{1} \mathrm{H}-\mathrm{NMR}$ (DMSO-d $\left.d_{6}\right) \delta: 10.09(\mathrm{~s}, 1 \mathrm{H}), 7.99-8.05(\mathrm{~m}, 3 \mathrm{H}), 7.93(\mathrm{~d}$, $J=6.9 \mathrm{~Hz}, 1 \mathrm{H}), 7.83(\mathrm{dd}, J=8.2 \mathrm{~Hz}, 1.3 \mathrm{~Hz}, 1 \mathrm{H}), 7.64(\mathrm{ddd}, J=8.2 \mathrm{~Hz}, 6.9 \mathrm{~Hz}, 1.0 \mathrm{~Hz}, 1 \mathrm{H}), 7.55-7.59$ $(\mathrm{m}, 2 \mathrm{H}), 7.39-7.43(\mathrm{~m}, 2 \mathrm{H}), 7.30(\mathrm{td}, J=7.8 \mathrm{~Hz}, 1.3 \mathrm{~Hz}, 1 \mathrm{H}), 3.87(\mathrm{sx}, J=5.9 \mathrm{~Hz}, 1 \mathrm{H}), 1.76-1.85(\mathrm{~m}, 2 \mathrm{H})$, $1.60-1.70(\mathrm{~m}, 2 \mathrm{H}), 1.46-1.55(\mathrm{~m}, 4 \mathrm{H}),{ }^{13} \mathrm{C}-\mathrm{NMR}$ (DMSO-d $\left.d_{6}\right), \delta: 164.39,153.66,145.26,134.69,130.58$, 130.34, 129.84, 129.62, 128.44, 128.07, 127.56, 127.43, 127.33, 127.33, 126.69, 125.81, 124.88, 122.74, 52.49, 32.14, 23.91; HR-MS: for $\mathrm{C}_{23} \mathrm{H}_{20} \mathrm{O}_{3} \mathrm{~N}_{2} \mathrm{Cl}[\mathrm{M}+\mathrm{H}]^{+}$calculated $409.13135 \mathrm{~m} / \mathrm{z}$, found $409.13258 \mathrm{~m} / \mathrm{z}$. 
1-[(2-Chlorophenyl) carbamoyl]naphthalen-2-yl cyclohexylcarbamate (12). Yield 34\%; Mp 129-132 ${ }^{\circ} \mathrm{C}$; IR $\left(\mathrm{cm}^{-1}\right)$ : 3245, 3218, 2931, 2854, 1717, 1664, 1544, 1525, 1510, 1479, 1463, 1436, 1317, 1295, 1272, $1254,1229,1150,1061,1027,1016,911,816,778,747,682 ;{ }^{1} \mathrm{H}-\mathrm{NMR}$ (DMSO-d $\left.d_{6}\right) \delta: 10.08$ (s, 1H), 7.99-8.05 $(\mathrm{m}, 3 \mathrm{H}), 7.86(\mathrm{~d}, J=7.7 \mathrm{~Hz}, 1 \mathrm{H}), 7.84(\mathrm{dd}, J=8.2 \mathrm{~Hz}, 1.3 \mathrm{~Hz}, 1 \mathrm{H}), 7.64(\mathrm{ddd}, J=8.2 \mathrm{~Hz}, 6.9 \mathrm{~Hz}$, $1.0 \mathrm{~Hz}, 1 \mathrm{H}), 7.55-7.59(\mathrm{~m}, 2 \mathrm{H}), 7.39-7.45(\mathrm{~m}, 2 \mathrm{H}), 7.30(\mathrm{td}, J=7.8 \mathrm{~Hz}, 1.3 \mathrm{~Hz}, 1 \mathrm{H}), 3.36-3.44(\mathrm{~m}, 1 \mathrm{H})$, $1.77-1.87(\mathrm{~m}, 2 \mathrm{H}), 1.66-1.72(\mathrm{~m}, 2 \mathrm{H}), 1.53-1.58(\mathrm{~m}, 1 \mathrm{H}), 1.21-1.29(\mathrm{~m}, 4 \mathrm{H}), 1.07-1.15(\mathrm{~m}, 1 \mathrm{H}),{ }^{13} \mathrm{C}-\mathrm{NMR}$ (DMSO- $d_{6}$ ), $\delta: 164.38,153.39,145.27,134.69,130.56,130.35,129.85,129.61,128.38,128.07,127.50,127.43$, 127.32, 127.31, 126.67, 125.80, 124.68, 122.68, 49.99, 32.50, 25.12, 24.60; HR-MS: for $\mathrm{C}_{24} \mathrm{H}_{22} \mathrm{O}_{3} \mathrm{~N}_{2} \mathrm{Cl}$ $[\mathrm{M}+\mathrm{H}]^{+}$calculated $423.14700 \mathrm{~m} / \mathrm{z}$, found $423.14818 \mathrm{~m} / \mathrm{z}$.

1-[(2-Chlorophenyl)carbamoyl]naphthalen-2-yl cycloheptylcarbamate (13). Yield 60\%; Mp 166-168 ${ }^{\circ} \mathrm{C}$; IR (cm $\left.{ }^{-1}\right)$ : 3295, 3204, 2919, 2855, 1732, 1708, 1656, 1582, 1544, 1521, 1506, 1475, 1441, 1429, 1342,

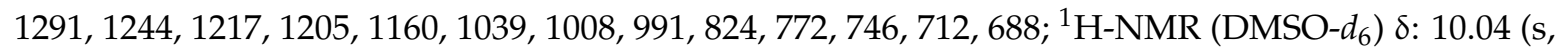
$1 \mathrm{H}), 7.99-8.05(\mathrm{~m}, 3 \mathrm{H}), 7.90(\mathrm{~d}, J=8.2 \mathrm{~Hz}, 1 \mathrm{H}), 7.85(\mathrm{dd}, J=8.2 \mathrm{~Hz}, 1.3 \mathrm{~Hz}, 1 \mathrm{H}), 7.64(\mathrm{ddd}, J=8.2 \mathrm{~Hz}$, $6.9 \mathrm{~Hz}, 1.0 \mathrm{~Hz}, 1 \mathrm{H}), 7.55-7.59(\mathrm{~m}, 2 \mathrm{H}), 7.39-7.45(\mathrm{~m}, 2 \mathrm{H}), 7.30(\mathrm{td}, J=7.8 \mathrm{~Hz}, 1.3 \mathrm{~Hz}, 1 \mathrm{H}), 3.52-3.60(\mathrm{~m}$, 1H), $1.80-1.86(\mathrm{~m}, 2 \mathrm{H}), 1.43-1.65(\mathrm{~m}, 8 \mathrm{H}), 1.32-1.42(\mathrm{~m}, 2 \mathrm{H}) ;{ }^{13} \mathrm{C}-\mathrm{NMR}$ (DMSO- $\left.d_{6}\right), \delta: 164.36,153.29$, 145.29, 134.68, 130.57, 130.34, 129.87, 129.60, 128.24, 128.06, 127.43, 127.34, 127.32, 127.25, 126.66, 125.80, 124.67, 122.70, 52.17, 34.35, 27.82, 23.58; HR-MS: for $\mathrm{C}_{25} \mathrm{H}_{24} \mathrm{O}_{3} \mathrm{~N}_{2} \mathrm{Cl}[\mathrm{M}+\mathrm{H}]^{+}$calculated $437.16265 \mathrm{~m} / z$, found $437.16342 \mathrm{~m} / \mathrm{z}$.

1-[(2-Chlorophenyl)carbamoyl]naphthalen-2-yl (2-phenylethyl)carbamate (14). Yield 38\%; Mp 115-118 ${ }^{\circ} \mathrm{C}$; IR ( $\left.\mathrm{cm}^{-1}\right)$ : 3316, 3221, 1731, 1661, 1583, 1538, 1511, 1467, 1443, 1307, 1248, 1229, 1221, 1200, 1162, 1059, 1031, 984, 817, 751, 739, 698; ${ }^{1} \mathrm{H}-\mathrm{NMR}$ (DMSO- $\left.\mathrm{d}_{6}\right) \delta: 10.13(\mathrm{~s}, 1 \mathrm{H}), 7.99-8.06(\mathrm{~m}, 4 \mathrm{H}), 7.84(\mathrm{dd}, J=8.1 \mathrm{~Hz}$, $1.4 \mathrm{~Hz}, 1 \mathrm{H}), 7.64(\mathrm{ddd}, J=8.2 \mathrm{~Hz}, 6.9 \mathrm{~Hz}, 1.0 \mathrm{~Hz}, 1 \mathrm{H}), 7.55-7.59(\mathrm{~m}, 2 \mathrm{H}), 7.43(\mathrm{td}, J=7.7 \mathrm{~Hz}, 1.6 \mathrm{~Hz}$, $1 \mathrm{H}), 7.37(\mathrm{~d}, J=9.1 \mathrm{~Hz}, 1 \mathrm{H}), 7.26-7.32(\mathrm{~m}, 4 \mathrm{H}), 7.21-7.23(\mathrm{~m}, 2 \mathrm{H}), 3.28-3.34(\mathrm{~m}, 2 \mathrm{H}), 2.78(\mathrm{t}, J=6.4 \mathrm{~Hz}$, 2H); ${ }^{13}$ C-NMR (DMSO- $d_{6}$ ), $\delta: 164.33,154.13,145.16,139.13,134.67,130.57,130.32,129.81,129.63,128.70$, 128.35, 128.28, 128.07, 127.50, 127.47, 127.33, 127.27, 126.55, 126.14, 125.82, 124.69, 122.55, 42.21, 35.23; HR-MS: for $\mathrm{C}_{26} \mathrm{H}_{20} \mathrm{O}_{3} \mathrm{~N}_{2} \mathrm{Cl}[\mathrm{M}+\mathrm{H}]^{+}$calculated 445.13135, found $445.13208 \mathrm{~m} / \mathrm{z}$.

1-[(2-Chlorophenyl)carbamoyl]naphthalen-2-yl (4-phenylbutyl)carbamate (15). Yield 58\%; Mp 132-134 ${ }^{\circ} \mathrm{C}$; IR $\left(\mathrm{cm}^{-1}\right)$ : 3220, 3024, 2938, 1719,1652, 1582, 1520, 1505, 1478, 1462, 1431, 1290, 1256, 1232, 1060, 985, 822, 760, 745, 699; ${ }^{1} \mathrm{H}-\mathrm{NMR}\left(\mathrm{DMSO}-d_{6}\right) \delta: 10.10(\mathrm{~s}, 1 \mathrm{H}), 7.99-8.05(\mathrm{~m}, 3 \mathrm{H}), 7.90(\mathrm{t}, J=5.5 \mathrm{~Hz}, 1 \mathrm{H}), 7.83$ $(\mathrm{dd}, J=8.2 \mathrm{~Hz}, 1.3 \mathrm{~Hz}, 1 \mathrm{H}), 7.63(\mathrm{ddd}, J=8.2 \mathrm{~Hz}, 6.9 \mathrm{~Hz}, 1.0 \mathrm{~Hz}, 1 \mathrm{H}), 7.54-7.59(\mathrm{~m}, 2 \mathrm{H}), 7.36-7.43$ $(\mathrm{m}, 3 \mathrm{H}), 7.24-7.31(\mathrm{~m}, 3 \mathrm{H}), 7.15-7.19(\mathrm{~m}, 2 \mathrm{H}), 3.10(\mathrm{q}, J=6.0 \mathrm{~Hz}, 2 \mathrm{H}), 2.55(\mathrm{t}, J=7.3 \mathrm{~Hz}, 2 \mathrm{H}), 1.59$ (qi, $J=7.3 \mathrm{~Hz}, 2 \mathrm{H}$ ), 1.48 (qi, $J=7.3 \mathrm{~Hz}, 2 \mathrm{H}$ ); ${ }^{13} \mathrm{C}-\mathrm{NMR}$ (DMSO-d 6 ), $8: 164.34,154.19,145.22,142.09$, $134.68,130.57,130.32,129.83,129.62$, 128.31, 128.23, 128.22, 128.07, 127.44, 127.42, 127.32, 127.26, 126.61, 125.81, 125.64, 124.68, 122.62, 40.39, 34.80, 28.88, 28.19; HR-MS: for $\mathrm{C}_{28} \mathrm{H}_{24} \mathrm{O}_{3} \mathrm{~N}_{2} \mathrm{Cl}[\mathrm{M}+\mathrm{H}]^{+}$calculated 473.16265 , found $473.16342 \mathrm{~m} / \mathrm{z}$.

1-[(2-Nitrophenyl)carbamoyl]naphthalen-2-yl ethylcarbamate (16). Yield 40\%; Mp 157-159 ${ }^{\circ} \mathrm{C} ; \mathrm{IR}\left(\mathrm{cm}^{-1}\right)$ : 3320, 3216, 2963, 2917, 2843, 1743, 1705, 1656, 1645, 1608, 1580, 1532, 1504, 1462, 1432, 1357, 1341, 1294, 1270, 1250, 1216, 1199, 1162, 1144, 1079, 1034, 993, 822, 791, 779, 732, 667; ${ }^{1}$ H-NMR (DMSO- $d_{6}$ ) $\delta: 10.94(\mathrm{~s}, 1 \mathrm{H}), 8.07(\mathrm{~d}, J=9.1 \mathrm{~Hz}, 1 \mathrm{H}), 8.01-8.05(\mathrm{~m}, 3 \mathrm{H}), 7.71-7.80(\mathrm{~m}, 3 \mathrm{H}), 7.65(\mathrm{ddd}, J=8.2 \mathrm{~Hz}$, $6.9 \mathrm{~Hz}, 1.4 \mathrm{~Hz}, 1 \mathrm{H}), 7.59(\mathrm{ddd}, J=8.2 \mathrm{~Hz}, 6.9 \mathrm{~Hz}, 1.4 \mathrm{~Hz}, 1 \mathrm{H}), 7.41-7.48(\mathrm{~m}, 2 \mathrm{H}), 3.04-3.11(\mathrm{~m}, 2 \mathrm{H}), 1.03$ $(\mathrm{t}, J=7.1 \mathrm{~Hz}, 3 \mathrm{H}) ;{ }^{13} \mathrm{C}-\mathrm{NMR}$ (DMSO- $\left.d_{6}\right), \delta: 164.12,153.71,145.56,142.98,133.89,130.62,130.51,130.33$, 130.26, 128.10, 127.42, 125.91, 125.82, 125.70, 124.96, 124.90, 124.43, 122.62, 35.39, 14.75; HR-MS: for $\mathrm{C}_{20} \mathrm{H}_{16} \mathrm{O}_{5} \mathrm{~N}_{3}[\mathrm{M}+\mathrm{H}]^{+}$calculated 378.10845, found $378.10934 \mathrm{~m} / \mathrm{z}$.

1-[(2-Nitrophenyl)carbamoyl]naphthalen-2-yl propylcarbamate (17). Yield 75\%; Mp 153-155 ${ }^{\circ} \mathrm{C}$; IR $\left(\mathrm{cm}^{-1}\right)$ : $3298,3223,2960,2930,2873,1727,1717,1662,1589,1537,1520,1505,1488,1463,1440,1353,1285,1257$, 1224, 1146, 1106, 1051, 996, 981, 914, 865, 818, 779, 731, 666; ${ }^{1} \mathrm{H}-\mathrm{NMR}$ (DMSO- $d_{6}$ ) $\delta: 10.93(\mathrm{~s}, 1 \mathrm{H}), 8.07$ $(\mathrm{d}, J=9.1 \mathrm{~Hz}, 1 \mathrm{H}), 8.01-8.05(\mathrm{~m}, 3 \mathrm{H}), 7.72-7.82(\mathrm{~m}, 3 \mathrm{H}), 7.65(\mathrm{ddd}, J=8.2 \mathrm{~Hz}, 6.9 \mathrm{~Hz}, 1.4 \mathrm{~Hz}, 1 \mathrm{H}), 7.59$ $(\mathrm{ddd}, J=8.2 \mathrm{~Hz}, 6.9 \mathrm{~Hz}, 1.4 \mathrm{~Hz}, 1 \mathrm{H}), 7.41-7.48(\mathrm{~m}, 2 \mathrm{H}), 3.00(\mathrm{q}, J=6.5 \mathrm{~Hz}, 2 \mathrm{H}), 1.42(\mathrm{sx}, J=7.1 \mathrm{~Hz}, 2 \mathrm{H})$, 
$0.80(\mathrm{t}, J=7.3 \mathrm{~Hz}, 3 \mathrm{H}) ;{ }^{13} \mathrm{C}-\mathrm{NMR}\left(\mathrm{DMSO}-d_{6}\right), \delta: 164.14,153.94,145.61,142.89,133.91,130.69,130.53$, 130.33, 130.33, 128.11, 127.43, 125.93, 125.79, 125.72, 125.64, 124.91, 124.46, 122.62, 42.29, 22.37, 11.10; HR-MS: for $\mathrm{C}_{21} \mathrm{H}_{18} \mathrm{O}_{5} \mathrm{~N}_{3}[\mathrm{M}+\mathrm{H}]^{+}$calculated 392.12410, found $392.12521 \mathrm{~m} / \mathrm{z}$.

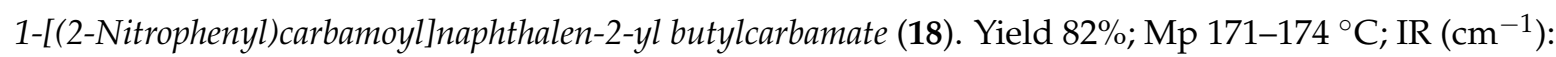
3293, 3222, 2957, 2873, 1724, 1661, 1589, 1549, 1532, 1520, 1505, 1471, 1463, 1439, 1350, 1279, 1257, 1227, 1145, 1109, 1006, 914, 865, 818, 779, 769, 731, 680, 667; ${ }^{1} \mathrm{H}-\mathrm{NMR}$ (DMSO-d $) \delta: 10.92$ (s, 1H), $8.07(\mathrm{~d}, J=9.1 \mathrm{~Hz}, 1 \mathrm{H}), 8.01-8.05(\mathrm{~m}, 3 \mathrm{H}), 7.73-7.80(\mathrm{~m}, 3 \mathrm{H}), 7.65(\mathrm{ddd}, J=8.2 \mathrm{~Hz}, 6.9 \mathrm{~Hz}, 1.4 \mathrm{~Hz}$, $1 \mathrm{H}), 7.58(\mathrm{ddd}, J=8.2 \mathrm{~Hz}, 6.9 \mathrm{~Hz}, 1.4 \mathrm{~Hz}, 1 \mathrm{H}), 7.45(\mathrm{td}, J=8.2 \mathrm{~Hz}, 1.4 \mathrm{~Hz}, 1 \mathrm{H}), 7.38(\mathrm{~d}, J=9.1 \mathrm{~Hz}$, $1 \mathrm{H}), 3.03(\mathrm{q}, J=6.2 \mathrm{~Hz}, 2 \mathrm{H}), 1.38(\mathrm{qi}, J=7.0 \mathrm{~Hz}, 2 \mathrm{H}), 1.23(\mathrm{sx}, J=7.0 \mathrm{~Hz}, 2 \mathrm{H}), 0.81(\mathrm{t}, J=7.1 \mathrm{~Hz}, 3 \mathrm{H})$; ${ }^{13}$ C-NMR (DMSO-d $)_{6}$, $\delta: ~ 164.13,153.91,145.58,142.77,133.91,130.74,130.52,130.32,130.31,128.10$, $127.41,125.91,125.74,125.73,125.56,124.91,124.44,122.59,40.18,31.23,19.27,13.58$; HR-MS: for $\mathrm{C}_{22} \mathrm{H}_{20} \mathrm{O}_{5} \mathrm{~N}_{3}[\mathrm{M}+\mathrm{H}]^{+}$calculated 406.13975 , found $406.14081 \mathrm{~m} / \mathrm{z}$.

1-[(2-Nitrophenyl)carbamoyl]naphthalen-2-yl pentylcarbamate (19). Yield 70\%; Mp 141-143 ${ }^{\circ} \mathrm{C} ; \mathrm{IR}\left(\mathrm{cm}^{-1}\right)$ : 3298, 3226, 2935, 2874, 1723, 1667, 1588, 1548, 1532, 1519, 1505, 1485, 1475, 1436, 1347, 1322, 1284, 1253, 1226, 1142, 1108, 1037, 1025, 996, 913, 866, 819, 778, 767, 730, 680, 660; ${ }^{1}$ H-NMR (DMSO- $d_{6}$ ) $\delta: 10.93$ (s, $1 \mathrm{H}), 8.07(\mathrm{~d}, J=9.1 \mathrm{~Hz}, 1 \mathrm{H}), 8.01-8.05(\mathrm{~m}, 3 \mathrm{H}), 7.75-7.81(\mathrm{~m}, 3 \mathrm{H}), 7.65(\mathrm{ddd}, J=8.2 \mathrm{~Hz}, 6.9 \mathrm{~Hz}, 1.4 \mathrm{~Hz}$, $1 \mathrm{H}), 7.58(\mathrm{ddd}, J=8.2 \mathrm{~Hz}, 6.9 \mathrm{~Hz}, 1.4 \mathrm{~Hz}, 1 \mathrm{H}), 7.45(\mathrm{td}, J=8.2 \mathrm{~Hz}, 1.4 \mathrm{~Hz}, 1 \mathrm{H}), 7.41(\mathrm{~d}, J=9.1 \mathrm{~Hz}, 1 \mathrm{H})$, $3.02(\mathrm{q}, J=6.4 \mathrm{~Hz}, 2 \mathrm{H}), 1.40(\mathrm{qi}, J=7.0 \mathrm{~Hz}, 2 \mathrm{H}), 1.09-1.33(\mathrm{~m}, 4 \mathrm{H}), 0.82(\mathrm{t}, J=6.2 \mathrm{~Hz}, 3 \mathrm{H}) ;{ }^{13} \mathrm{C}-\mathrm{NMR}$ $\left(\right.$ DMSO$_{-}$) $), \delta: 164.12,153.89,145.58,142.80,133.88,130.72,130.51,130.31,130.30,128.10,127.42,125.91$, $125.74,125.72,125.58,124.91,124.44,122.61,40.47,28.77,28.29,21.76,13.83$; HR-MS: for $\mathrm{C}_{23} \mathrm{H}_{22} \mathrm{O}_{5} \mathrm{~N}_{3}$ $[\mathrm{M}+\mathrm{H}]^{+}$calculated 420.15540 , found $420.15643 \mathrm{~m} / \mathrm{z}$.

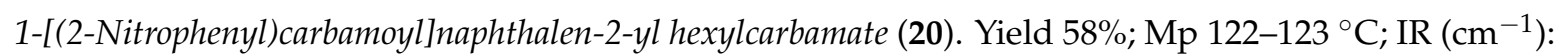
$3332,3272,2929,2868,1709,1665,1609,1589,1541,1514,1472,1443,1352,1295,1250,1215,1205,1158$, $1148,1113,1046,993,978,911,863,825,779,761,738,697,672 ;{ }^{1} \mathrm{H}-\mathrm{NMR}$ (DMSO-d $) \delta: 10.93(\mathrm{~s}, 1 \mathrm{H})$, $8.07(\mathrm{~d}, J=9.1 \mathrm{~Hz}, 1 \mathrm{H}), 8.01-8.05(\mathrm{~m}, 3 \mathrm{H}), 7.75-7.81(\mathrm{~m}, 3 \mathrm{H}), 7.65(\mathrm{ddd}, J=8.2 \mathrm{~Hz}, 6.9 \mathrm{~Hz}, 1.4 \mathrm{~Hz}, 1 \mathrm{H})$, $7.58(\mathrm{ddd}, J=8.2 \mathrm{~Hz}, 6.9 \mathrm{~Hz}, 1.4 \mathrm{~Hz}, 1 \mathrm{H}), 7.45(\mathrm{td}, J=8.2 \mathrm{~Hz}, 1.4 \mathrm{~Hz}, 1 \mathrm{H}), 7.41(\mathrm{~d}, J=9.1 \mathrm{~Hz}, 1 \mathrm{H}), 3.02(\mathrm{q}$, $J=6.0 \mathrm{~Hz}, 2 \mathrm{H}), 1.38(\mathrm{qi}, J=6.4 \mathrm{~Hz}, 2 \mathrm{H}), 1.18-1.25(\mathrm{~m}, 6 \mathrm{H}), 0.83(\mathrm{t}, J=6.6 \mathrm{~Hz}, 3 \mathrm{H}) ;{ }^{13} \mathrm{C}-\mathrm{NMR}\left(\mathrm{DMSO}-d_{6}\right)$, $\delta: 164.65,154.44,146.08,143.25,134.42,131.24,131.04,130.83,130.82,128.61,127.94,126.44,126.23$, $126.23,126.06,125.42,124.94,123.10,41.03,31.42,29.56,26.28,22.49,14.38$; HR-MS: for $\mathrm{C}_{24} \mathrm{H}_{24} \mathrm{O}_{5} \mathrm{~N}_{3}$ $[\mathrm{M}+\mathrm{H}]^{+}$calculated 434.17105 , found $434.17236 \mathrm{~m} / \mathrm{z}$.

1-[(2-Nitrophenyl)carbamoyl]naphthalen-2-yl heptylcarbamate (21). Yield 46\%; Mp 101-102 $\left.{ }^{\circ} \mathrm{C} ; \mathrm{IR}_{(\mathrm{cm}}{ }^{-1}\right)$ : $3333,3265,2957,2925,2852,1709,1665,1652,1609,1588,1541,1511,1472,1464,1441,1350,1294,1250$, $1215,1205,1148,1045,979,911,824,779,755,737,696,667 ;{ }^{1} \mathrm{H}-\mathrm{NMR}$ (DMSO- $\left.d_{6}\right) \delta: 10.93(\mathrm{~s}, 1 \mathrm{H}), 8.07$ $(\mathrm{d}, J=9.1 \mathrm{~Hz}, 1 \mathrm{H}), 8.01-8.05(\mathrm{~m}, 3 \mathrm{H}), 7.75-7.81(\mathrm{~m}, 3 \mathrm{H}), 7.65(\mathrm{ddd}, J=8.2 \mathrm{~Hz}, 6.9 \mathrm{~Hz}, 1.4 \mathrm{~Hz}, 1 \mathrm{H})$, $7.58(\mathrm{ddd}, J=8.2 \mathrm{~Hz}, 6.9 \mathrm{~Hz}, 1.4 \mathrm{~Hz}, 1 \mathrm{H}), 7.45(\mathrm{td}, J=8.2 \mathrm{~Hz}, 1.4 \mathrm{~Hz}, 1 \mathrm{H}), 7.41(\mathrm{~d}, J=9.1 \mathrm{~Hz}, 1 \mathrm{H})$, $3.02(\mathrm{q}, J=6.3 \mathrm{~Hz}, 2 \mathrm{H}), 1.39(\mathrm{qi}, J=6.4 \mathrm{~Hz}, 2 \mathrm{H}), 1.17-1.28(\mathrm{~m}, 8 \mathrm{H}), 0.85(\mathrm{t}, J=6.6 \mathrm{~Hz}, 3 \mathrm{H}) ;{ }^{13} \mathrm{C}-\mathrm{NMR}$ $\left(\right.$ DMSO- $\left._{6}\right)$, $\delta:$ 164.12, 153.89, 145.58, 142.77, 133.88, 130.74, 130.53, 130.31, 130.31, 128.10, 127.42, 125.91, $125.73,125.72,125.58,124.90,124.44,122.61,40.50,31.16,29.11,28.36,26.07,22.04,13.93$; HR-MS: for $\mathrm{C}_{25} \mathrm{H}_{26} \mathrm{O}_{5} \mathrm{~N}_{3}[\mathrm{M}+\mathrm{H}]^{+}$calculated 448.18670 , found $448.18848 \mathrm{~m} / \mathrm{z}$.

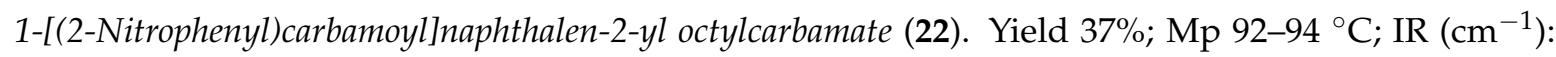
3315, 3230, 2924, 2850, 1704, 1653, 1589, 1528, 1508, 1485, 1463, 1435, 1360, 1293, 1271, 1251, 1219, 915, 834, 780, 759, 736, 701, 667; ${ }^{1} \mathrm{H}-\mathrm{NMR}\left(\mathrm{DMSO}-\mathrm{d}_{6}\right) \delta: 10.93$ (s, 1H), 8.07 (d, J = 9.1 Hz, 1H), 8.01-8.05 $(\mathrm{m}, 3 \mathrm{H}), 7.75-7.81(\mathrm{~m}, 3 \mathrm{H}), 7.65(\mathrm{ddd}, J=8.2 \mathrm{~Hz}, 6.9 \mathrm{~Hz}, 1.4 \mathrm{~Hz}, 1 \mathrm{H}), 7.59(\mathrm{ddd}, J=8.2 \mathrm{~Hz}, 6.9 \mathrm{~Hz}$, $1.4 \mathrm{~Hz}, 1 \mathrm{H}), 7.46(\mathrm{td}, J=8.2 \mathrm{~Hz}, 1.4 \mathrm{~Hz}, 1 \mathrm{H}), 7.41(\mathrm{~d}, J=9.1 \mathrm{~Hz}, 1 \mathrm{H}), 3.03(\mathrm{q}, J=5.5 \mathrm{~Hz}, 2 \mathrm{H}), 1.39$ (qi, $J=6.0 \mathrm{~Hz}, 2 \mathrm{H}), 1.18-1.29(\mathrm{~m}, 10 \mathrm{H}), 0.86(\mathrm{t}, J=6.4 \mathrm{~Hz}, 3 \mathrm{H}) ;{ }^{13} \mathrm{C}-\mathrm{NMR}\left(\mathrm{DMSO}-d_{6}\right), \delta: 164.12,153.89$, $145.58,142.79,133.86,130.72,130.51,130.32,130.31,128.10,127.42,125.91,125.75,125.72,125.58,124.90$, $124.44,122.59,40.50,31.22,29.09,28.67,28.59,26.12,22.07,13.95 ; \mathrm{HR}-\mathrm{MS}$ : for $\mathrm{C}_{26} \mathrm{H}_{28} \mathrm{O}_{5} \mathrm{~N}_{3}[\mathrm{M}+\mathrm{H}]^{+}$ calculated 462.20235 , found $462.20410 \mathrm{~m} / \mathrm{z}$. 
1-[(2-Nitrophenyl)carbamoyl]naphthalen-2-yl isoproylcarbamate (23). Yield 69\%; Mp 172-176 ${ }^{\circ} \mathrm{C} ; \mathrm{IR}\left(\mathrm{cm}^{-1}\right)$ : $3355,3320,2974,1738,1665,1586,1532,1505,1489,1440,1362,1245,1213,1173,1149,1056,1018$, 953, 924, 826, 778, 763, 732; ${ }^{1} \mathrm{H}-\mathrm{NMR}\left(\mathrm{DMSO}-\mathrm{d}_{6}\right) \delta: 10.93$ (s, 1H), 8.07 (d, J = 9.1 Hz, 1H), 8.01-8.05 $(\mathrm{m}, 3 \mathrm{H}), 7.75-7.80(\mathrm{~m}, 3 \mathrm{H}), 7.66(\mathrm{ddd}, J=8.2 \mathrm{~Hz}, 6.9 \mathrm{~Hz}, 1.4 \mathrm{~Hz}, 1 \mathrm{H}), 7.59(\mathrm{ddd}, J=8.2 \mathrm{~Hz}, 6.9 \mathrm{~Hz}$, $1.4 \mathrm{~Hz}, 1 \mathrm{H}), 7.46(\mathrm{td}, J=8.2 \mathrm{~Hz}, 1.4 \mathrm{~Hz}, 1 \mathrm{H}), 7.42(\mathrm{~d}, J=9.1 \mathrm{~Hz}, 1 \mathrm{H}), 3.65(\mathrm{sx}, J=6.4 \mathrm{~Hz}, 2 \mathrm{H}), 1.07(\mathrm{~d}$, $J=6.4 \mathrm{~Hz}, 6 \mathrm{H}) ;{ }^{13} \mathrm{C}-\mathrm{NMR}\left(\mathrm{DMSO}-d_{6}\right), \delta: 164.18,153.10,145.61,142.94,133.92,130.69,130.54,130.37$, 130.33, 128.14, 127.46, 125.96, 125.85, 125.80, 125.72, 124.94, 124.46, 122.71, 42.86, 22.32; HR-MS: for $\mathrm{C}_{21} \mathrm{H}_{18} \mathrm{O}_{5} \mathrm{~N}_{3}[\mathrm{M}+\mathrm{H}]^{+}$calculated 394.13975 , found $394.14058 \mathrm{~m} / \mathrm{z}$.

1-[(2-Nitrophenyl)carbamoyl]naphthalen-2-yl cyclopentylcarbamate (24). Yield 28\%; Mp $138-142{ }^{\circ} \mathrm{C}$; IR (cm $\left.{ }^{-1}\right): 3295,3219,2960,1719,1661,1588,1519,1487,1438,1351,1283,1255,1222,1144,1078$, 998, 822, 779, 732, 667; ${ }^{1} \mathrm{H}-\mathrm{NMR}\left(\mathrm{DMSO}_{6}\right) \delta$ : $10.92(\mathrm{~s}, 1 \mathrm{H}), 8.07$ (d, J = 9.1 Hz, 1H), 8.01-8.05 (m, $3 \mathrm{H}), 7.84(\mathrm{~d}, J=6.9 \mathrm{~Hz}, 1 \mathrm{H}), 7.72-7.79(\mathrm{~m}, 2 \mathrm{H}), 7.65(\mathrm{ddd}, J=8.2 \mathrm{~Hz}, 6.9 \mathrm{~Hz}, 1.4 \mathrm{~Hz}, 1 \mathrm{H}), 7.59$ (ddd, $J=8.2 \mathrm{~Hz}, 6.9 \mathrm{~Hz}, 1.4 \mathrm{~Hz}, 1 \mathrm{H}), 7.46(\mathrm{td}, J=8.2 \mathrm{~Hz}, 1.4 \mathrm{~Hz}, 1 \mathrm{H}), 7.42(\mathrm{~d}, J=9.1 \mathrm{~Hz}, 1 \mathrm{H}), 3.83(\mathrm{sx}$, $J=5.5 \mathrm{~Hz}, 1 \mathrm{H}), 1.72-1.80(\mathrm{~m}, 2 \mathrm{H}), 1.56-1.63(\mathrm{~m}, 2 \mathrm{H}), 1.42-1.49(\mathrm{~m}, 4 \mathrm{H}) ;{ }^{13} \mathrm{C}-\mathrm{NMR}\left(\mathrm{DMSO}-d_{6}\right), \delta: 164.18$, $153.41,145.64,142.94,133.92,130.69,130.55,130.36,130.34,128.14,127.46,125.97,125.86,125.80,125.72$, $124.95,124.45,122.73,52.47,32.06,23.29$; HR-MS: for $\mathrm{C}_{23} \mathrm{H}_{20} \mathrm{O}_{5} \mathrm{~N}_{3}[\mathrm{M}+\mathrm{H}]^{+}$calculated 420.15540, found $420.15620 \mathrm{~m} / \mathrm{z}$.

1-[(2-Nitrophenyl)carbamoyl]naphthalen-2-yl cyclohexylcarbamate (25). Yield 54\%; Mp 140-143 ${ }^{\circ} \mathrm{C}$; IR $\left(\mathrm{cm}^{-1}\right):$ 3328, 3297, 2937, 2911, 2858, 1705, 1662, 1589, 1536, 1514, 1505, 1472, 1440, 1354, 1312, 1292, 1209, 1146, 1049, 1014, 823, 779, 761, 733, 697; ${ }^{1} \mathrm{H}-\mathrm{NMR}\left(\mathrm{DMSO}-d_{6}\right) \delta: 10.91(\mathrm{~s}, 1 \mathrm{H}), 8.07$ (d, $J=9.1 \mathrm{~Hz}$, 1H), 8.01-8.05 (m, 3H), 7.72-7.79 (m, 3H), $7.65(\mathrm{ddd}, J=8.2 \mathrm{~Hz}, 6.9 \mathrm{~Hz}, 1.4 \mathrm{~Hz}, 1 \mathrm{H}), 7.58(\mathrm{ddd}, J=8.2 \mathrm{~Hz}$, $6.9 \mathrm{~Hz}, 1.4 \mathrm{~Hz}, 1 \mathrm{H}), 7.45(\mathrm{td}, J=8.2 \mathrm{~Hz}, 1.4 \mathrm{~Hz}, 1 \mathrm{H}), 7.41(\mathrm{~d}, J=9.1 \mathrm{~Hz}, 1 \mathrm{H}), 3.26-3.33(\mathrm{~m}, 1 \mathrm{H}), 1.71-1.76$ $(\mathrm{m}, 2 \mathrm{H}), 1.63-1.68(\mathrm{~m}, 2 \mathrm{H}), 1.51-1.56(\mathrm{~m}, 1 \mathrm{H}), 1.02-1.27(\mathrm{~m}, 5 \mathrm{H}) ;{ }^{13} \mathrm{C}-\mathrm{NMR}$ (DMSO-d 6$), \delta: 164.17,153.14$, $145.65,142.90,133.91,130.70,130.53,130.36,130.35,128.13,127.46,125.96,125.82,125.79,125.69,124.93$, $124.45,122.67,49.96,32.39,25.10,24.56$; HR-MS: for $\mathrm{C}_{24} \mathrm{H}_{22} \mathrm{O}_{5} \mathrm{~N}_{3}[\mathrm{M}+\mathrm{H}]^{+}$calculated 434.17105, found $434.17208 \mathrm{~m} / \mathrm{z}$.

1-[(2-Nitrophenyl)carbamoyl]naphthalen-2-yl cycloheptylcarbamate (26). Yield 58\%; Mp $142-145{ }^{\circ} \mathrm{C}$; IR $\left(\mathrm{cm}^{-1}\right)$ : 3324, 2912, 2855, 1703, 1662, 1588, 1528, 1505, 1472, 1440, 1353, 1291, 1245, 1218, 1203, 1141, 1041, 997, 909, 823, 779, 758, 737, 697; ${ }^{1} \mathrm{H}-\mathrm{NMR}\left(\mathrm{DMSO}-\mathrm{d}_{6}\right) \delta: 10.91(\mathrm{~s}, 1 \mathrm{H}), 8.06(\mathrm{~d}, J=9.1 \mathrm{~Hz}$, $1 \mathrm{H}), 8.01-8.05(\mathrm{~m}, 3 \mathrm{H}), 7.81(\mathrm{~d}, J=8.2 \mathrm{~Hz}, 1 \mathrm{H}), 7.72-7.78(\mathrm{~m}, 2 \mathrm{H}), 7.65$ (ddd, J = 8.2 Hz, 6.9 Hz, $1.4 \mathrm{~Hz}$, 1H), $7.58(\mathrm{ddd}, J=8.2 \mathrm{~Hz}, 6.9 \mathrm{~Hz}, 1.4 \mathrm{~Hz}, 1 \mathrm{H}), 7.45(\mathrm{td}, J=8.2 \mathrm{~Hz}, 1.4 \mathrm{~Hz}, 1 \mathrm{H}), 7.41(\mathrm{~d}, J=9.1 \mathrm{~Hz}$, 1H), 3.46-3.54 (m, 1H), 1.73-1.80 (m, 2H), 1.39-1.60 (m, 8H), 1.29-1.38 (m, 2H); ${ }^{13}$ C-NMR (DMSO- $\left.d_{6}\right)$, $\delta: 164.18,153.01,145.67,142.82,133.92,130.73,130.54,130.35,130.35,128.13,127.45,125.95,125.80$, $125.80,125.63,124.93,124.45,122.70,52.13,34.26,27.80,23.54 ; \mathrm{HR}-\mathrm{MS}$ : for $\mathrm{C}_{25} \mathrm{H}_{24} \mathrm{O}_{5} \mathrm{~N}_{3}[\mathrm{M}+\mathrm{H}]^{+}$ calculated 448.18670 , found $448.18784 \mathrm{~m} / \mathrm{z}$.

1-[(2-Nitrophenyl)carbamoyl]naphthalen-2-yl (2-phenylethyl)carbamate (27). Yield 32\%; Mp $127-130{ }^{\circ} \mathrm{C}$; IR $\left(\mathrm{cm}^{-1}\right)$ : 3336, 1742, 1708, 1683, 1608, 1578, 1535, 1510, 1495, 1434, 1398, 1334, 1270, 1211, 1144, 1130, 967, 824, 758, 743, 698; ${ }^{1} \mathrm{H}-\mathrm{NMR}\left(\mathrm{DMSO}_{6}\right) \delta: 10.96(\mathrm{~s}, 1 \mathrm{H}), 8.07(\mathrm{~d}, J=9.1 \mathrm{~Hz}, 1 \mathrm{H}), 8.01-8.05(\mathrm{~m}, 3 \mathrm{H})$, $7.91(\mathrm{t}, J=5.7 \mathrm{~Hz}, 1 \mathrm{H}), 7.71-7.79(\mathrm{~m}, 2 \mathrm{H}), 7.65(\mathrm{ddd}, J=8.2 \mathrm{~Hz}, 6.9 \mathrm{~Hz}, 1.4 \mathrm{~Hz}, 1 \mathrm{H}), 7.59(\mathrm{ddd}, J=8.2 \mathrm{~Hz}$, $6.9 \mathrm{~Hz}, 1.4 \mathrm{~Hz}, 1 \mathrm{H}), 7.46(\mathrm{td}, J=8.2 \mathrm{~Hz}, 1.4 \mathrm{~Hz}, 1 \mathrm{H}), 7.38(\mathrm{~d}, J=9.1 \mathrm{~Hz}, 1 \mathrm{H}), 7.17-7.26(\mathrm{~m}, 5 \mathrm{H}), 3.26(\mathrm{q}$, $J=6.4 \mathrm{~Hz}, 2 \mathrm{H}), 2.73(\mathrm{t}, J=7.3 \mathrm{~Hz}, 2 \mathrm{H}) ;{ }^{13} \mathrm{C}-\mathrm{NMR}\left(\mathrm{DMSO}-d_{6}\right), \delta: 164.10,153.87,145.54,143.01,139.13$, 133.94, 130.63, 130.54, 130.35, 130.31, 128.88, 128.72, 128.31, 128.14, 127.46, 126.10, 125.98, 125.82, 123.69, 124.94, 124.48, 122.58, 42.16, 35.11; HR-MS: for $\mathrm{C}_{26} \mathrm{H}_{20} \mathrm{O}_{5} \mathrm{~N}_{3}[\mathrm{M}+\mathrm{H}]^{+}$calculated 456.15540, found $456.15712 \mathrm{~m} / \mathrm{z}$.

1-[(2-Nitrophenyl)carbamoyl]naphthalen-2-yl (4-phenylbutyl)carbamate (28). Yield 47\%; Mp 109-110 ${ }^{\circ} \mathrm{C}$; IR (cm $\left.{ }^{-1}\right)$ : 3351, 3233, 2934, 1714, 1677, 1593, 1519, 1505, 1482, 1458, 1435, 1352, 1287, 1244, 1222, 1051, 1007, 816, 779, 752, 731, 967; ${ }^{1} \mathrm{H}-\mathrm{NMR}$ (DMSO-d (D) 10.94 (s, 1H), 8.07 (d, J = 8.7 Hz, 1H), 8.00-8.05 $(\mathrm{m}, 3 \mathrm{H}), 7.82(\mathrm{t}, J=5.7 \mathrm{~Hz}, 1 \mathrm{H}), 7.70-7.72(\mathrm{~m}, 2 \mathrm{H}), 7.65(\mathrm{ddd}, J=8.2 \mathrm{~Hz}, 6.9 \mathrm{~Hz}, 1.4 \mathrm{~Hz}, 1 \mathrm{H}), 7.58(\mathrm{ddd}$, 
$J=8.2 \mathrm{~Hz}, 6.9 \mathrm{~Hz}, 1.4 \mathrm{~Hz}, 1 \mathrm{H}), 7.43-7.46(\mathrm{~m}, 1 \mathrm{H}), 7.41(\mathrm{~d}, J=9.1 \mathrm{~Hz}, 1 \mathrm{H}), 7.24-7.28(\mathrm{~m}, 2 \mathrm{H}), 7.15-7.18$ $(\mathrm{m}, 3 \mathrm{H}), 3.06(\mathrm{q}, J=5.9 \mathrm{~Hz}, 2 \mathrm{H}), 2.52(\mathrm{t}, J=7.3 \mathrm{~Hz}, 2 \mathrm{H}), 1.54(\mathrm{qi}, J=7.3 \mathrm{~Hz}, 2 \mathrm{H}), 1.43(\mathrm{qi}, J=7.3 \mathrm{~Hz}, 2 \mathrm{H})$; ${ }^{13}$ C-NMR (DMSO- $d_{6}$ ), $\delta: 164.13,153.93,145.59,142.96,142.09,133.88,130.65,130.54,130.35,130.32$, 128.30, 128.22, 128.13, 127.45, 125.95, 125.80, 125.72, 125.64, 125.64, 124.93, 124.47, 122.63, 40.32, 34.77, 28.80, 28.11; HR-MS: for $\mathrm{C}_{28} \mathrm{H}_{24} \mathrm{O}_{5} \mathrm{~N}_{3}[\mathrm{M}+\mathrm{H}]^{+}$calculated 484.18670, found $484.18801 \mathrm{~m} / z$.

\subsection{In Vitro Antibacterial Susceptibility Testing}

The synthesized compounds were evaluated for in vitro antibacterial activity against representatives of multidrug-resistant bacteria and clinical isolates of methicillin-resistant Staphylococcus aureus (MRSA) SA 630 and SA 3202, that were obtained from the National Institute of Public Health (Prague, Czech Republic). Staphylococcus aureus ATCC 29213 was used as a reference and quality control strain. Ampicillin (Sigma-Aldrich) was used as the standard. Prior to testing, each strain was passaged onto nutrient agar (Oxoid, Hampshire, UK) with 5\% of bovine blood, and bacterial inocula were prepared by suspending a small portion of bacterial colony in sterile phosphate buffered saline ( $\mathrm{pH} 7.2-7.3)$. The cell density was adjusted to $0.5 \mathrm{McF}$ arland units using a densitometer (Densi-La-Meter, LIAP, Riga, Latvia). The final inoculum was made to a 1:20 dilution of the suspension with the Mueller-Hinton broth (MH broth). The compounds were dissolved in DMSO (Sigma), and the final concentration of DMSO in the MH broth (Oxoid) did not exceed $2.5 \%$ of the total solution composition. The final concentrations of the evaluated compounds ranged from $256 \mu \mathrm{g} / \mathrm{mL}$ to $0.008 \mu \mathrm{g} / \mathrm{mL}$. The broth dilution micro-method, modified according to NCCLS (National Committee for Clinical Laboratory Standards) guidelines [46,47] in MH broth, was used to determine the minimum inhibitory concentration (MIC). Drug-free controls, sterility controls, and controls consisting of MH broth and DMSO alone were included. The determination of results was performed visually after $24 \mathrm{~h}$ of static incubation in the darkness at $37^{\circ} \mathrm{C}$ in an aerobic atmosphere. The MICs were defined as the lowest concentration of the compound at which no visible bacterial growth was observed. The results are summarized in Table 1.

\subsection{In Vitro Antimycobacterial Evaluation}

The evaluation of the in vitro antimycobacterial activity of the compounds was performed against Mycobacterium marinum CAMP 5644 and M. kansasii DSM 44162. The broth dilution micro-method in Middlebrook 7H9 medium (Difco, Lawrence, KS, USA) supplemented with ADC Enrichment (Becton, Dickinson \& Comp., Franklin Lakes, NJ, USA) was used to determine the minimum inhibitory concentration (MIC), as previously described [48]. The compounds were dissolved in DMSO (Sigma-Aldrich), and the final concentration of DMSO did not exceed $2.5 \%$ of the total solution composition. The final concentrations of the evaluated compounds, ranging from $256 \mu \mathrm{g} / \mathrm{mL}$ to $0.125 \mu \mathrm{g} / \mathrm{mL}$, were obtained by twofold serial dilution of the stock solution in a microtiter plate with sterile medium. Bacterial inocula were prepared by transferring colonies from the culture to sterile water. The cell density was adjusted to $0.5 \mathrm{McF}$ arland units using a densitometer (Densi-La-Meter, LIAP, Riga, Latvia). The final inoculum was made by 1:1000 dilution of the suspension with sterile water. Drug-free controls, sterility controls, and controls consisting of the medium and DMSO alone were included. The determination of results was performed visually after 7 days of static incubation in the darkness at $37^{\circ} \mathrm{C}$ in an aerobic atmosphere for $M$. kansasii and after 21 days of static incubation in the darkness at $28^{\circ} \mathrm{C}$ in an aerobic atmosphere for M. marinum. The minimum inhibitory concentration (MIC) was defined as the lowest concentration of the compound at which no visible bacterial growth was observed. The MIC value is routinely and widely used in bacterial assays and is a standard detection limit according to the Clinical and Laboratory Standards Institute (CLSI) [49]. Isoniazid (Sigma-Aldrich) was used as the reference antibacterial drug. The results are summarized in Table 1. 


\subsection{In Vitro Cytotoxicity Assay}

Human monocytic leukemia THP-1 cells were obtained from the European Collection of Cell Cultures (ECACC, Salisbury, UK; Methods of characterization: DNA Fingerprinting (Multilocus probes) and isoenzyme analysis). These cells were routinely cultured in RPMI 1640 (Lonza, Verviers, Belgium) medium supplemented with 10\% fetal bovine serum (FBS, Sigma-Aldrich), $2 \%$ L-glutamine, $1 \%$ penicillin, and streptomycin (Lonza, Verviers, Belgium) at $37^{\circ} \mathrm{C}$ with $5 \% \mathrm{CO}_{2}$. Cells were passaged at approximately 1-week intervals. Cells were routinely tested for the absence of mycoplasma (Hoechst 33258 staining method). The tested compounds were dissolved in DMSO (Sigma-Aldrich) and added in five increasing concentrations to the cell suspension in the culture medium. The maximum concentration of DMSO in the assays never exceeded $0.1 \%$. Subsequently, the cells were incubated for $24 \mathrm{~h}$ at $37{ }^{\circ} \mathrm{C}$ with $5 \% \mathrm{CO}_{2}$ at various compound concentrations ranging from 0.37 to $30 \mu \mathrm{mol} / \mathrm{L}$ in RPMI 1640 medium. Cell toxicity was determined using a Cytotoxicity Detection Kit ${ }^{\text {PLUS }}$ Lactate dehydrogenase (LDH) assay kit (Roche Diagnostics, Mannheim, Germany), and used according to the manufacturer's instructions, as described previously [14,30,32,33]. For LDH assays, cells were seeded

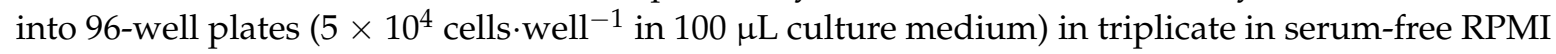
1640 medium, and measurements at $492 \mathrm{~nm}$ wavelength (Synergy 2 Multi-Mode Microplate Reader, BioTek, Winooski, VT, USA) were taken $24 \mathrm{~h}$ after the treatment with tested compounds. The median lethal dose values, $\mathrm{LD}_{50}$, were deduced through the production of a dose-response curve. All data were evaluated using GraphPad Prism 5.00 software (GraphPad Software, San Diego, CA, USA). The results are summarized in Table 1.

\section{Conclusions}

Series of thirteen 1-[(2-chlorophenyl)carbamoyl]naphthalen-2-yl carbamates and thirteen 1-[(2-nitrophenyl)carbamoyl]naphthalen-2-yl carbamates were prepared and subsequently characterized. All compounds were tested for their in vitro antimicrobial activity against $S$. aureus, two methicillin-resistant S. aureus strains, M. marinum, and M. kansasii. 1-[(2-Chlorophenyl)-carbamoyl]naphthalen-2-yl ethylcarbamate (3) and 1-[(2-nitrophenyl)carbamoyl]naphthalen-2-yl ethylcarbamate (16) showed MICs $=42 \mu \mathrm{M}$ against all methicillin-resistant $S$. aureus strains. In addition, both compounds expressed MICs $=21 \mu \mathrm{M}$ against $M$. marinum and $M$. kansasii. Propyl- $(4,17)$ and isopropyl- $(\mathbf{1 0}, \mathbf{2 3})$ carbamates demonstrated medium antimicrobial activity, while bulkier-substituted carbamates showed only moderate or no activity, which was similar in both the chlorinated and nitrated series. Screening of the cytotoxicity of the most potent and discussed compounds, performed using the THP-1 cells, proved no significant lethal effect $\left(\mathrm{LD}_{50}>30 \mu \mathrm{M}\right)$. The biological activity of the compounds is dependent on the alkyl substitution of carbamate nitrogen. Spatially small $N$-alkyl substituents are important for the activity. Antimicrobial activity rapidly decreases with chain prolongation or with a bulkier $\mathrm{N}$-cycloalkyl, $\mathrm{N}$-arylalkyl substituent.

Acknowledgments: This study was supported by IGA VFU Brno 311/2016/FaF, 328/2016/FaF, 302/2015/FaF, 320/2015/FaF and by the Slovak Research and Development Agency (Grant No. APVV-0516-12). The HPLC/HRMS system forms a part of the National Infrastructure CzeCOS (LM2015061); Michal Oravec was supported by the National Sustainability Program (NPU I; Grant No. LO1415 POLYMAT).

Author Contributions: Tomas Gonec, Josef Stranik, Jiri Kos, Josef Jampilek-design, synthesis of the compounds, SAR, writing of the paper. Michal Oravec, Aneta Cernikova-analysis/characterization of the compounds. Sarka Pospisilova, Valeria Pudelkova, Alois Cizek-antimicrobial evaluation. Lucie Holanova, Peter Kollar-cytotoxicity assay.

Conflicts of Interest: The authors declare no conflict of interest.

\section{References}

1. World Health Organization. World Health Statistics 2016: Monitoring Health for the SDGs; WHO Press: Geneva, Switzerland, 2016.

2. World Health Organization. Global Tuberculosis Report 2015; WHO Press: Geneva, Switzerland, 2015. 
3. World Health Organization. Global Antimicrobial Resistance Surveillance System 2015; WHO Press: Geneva, Switzerland, 2015.

4. European Centre for Disease Prevention and Control. Available online: http://ecdc.europa.eu/en/Pages/ home.aspx (accessed on 30 July 2016).

5. Thampi, N.; Showler, A.; Burry, L.; Bai, A.D.; Steinberg, M.; Ricciuto, D.R.; Bell, C.M.; Morris, A.M. Multicenter study of health care cost of patients admitted to hospital with Staphylococcus aureus bacteremia: Impact of length of stay and intensity of care. Am. J. Infect. Control. 2015, 43, 739-744. [CrossRef] [PubMed]

6. Kaku, N.; Yanagihara, K.; Morinaga, Y.; Yamada, K.; Harada, Y.; Migiyama, Y.; Nagaoka, K.; Matsuda, J.; Uno, N.; Hasegawa, H.; et al. Influence of antimicrobial regimen on decreased in-hospital mortality of patients with MRSA bacteremia. J. Infect. Chemother. 2014, 20, 350-355. [CrossRef] [PubMed]

7. Tavares, L.S.; Silva, C.S.F.; de Souza, V.C.; da Silva, V.L.; Diniz, C.G.; Santos, M.O. Strategies and molecular tools to fight antimicrobial resistance: Resistome, transcriptome, and antimicrobial peptides. Front. Microbiol. 2013, 4, 412. [CrossRef] [PubMed]

8. Jampilek, J. Potential of agricultural fungicides for antifungal drug discovery. Expert Opin. Drug Dis. 2016, 11, 1-9. [CrossRef] [PubMed]

9. Jampilek, J. How Can We Bolster the Antifungal Drug Discovery Pipeline? Future Med. Chem. 2016, 8, 1393-1397. [CrossRef] [PubMed]

10. Kratky, M.; Vinsova, J. Salicylanilide ester prodrugs as potential antimicrobial agents-A review. Curr. Pharm. Des. 2011, 17, 3494-3505. [CrossRef] [PubMed]

11. Imramovsky, A.; Pauk, K.; Pejchal, V.; Hanusek, J. Salicylanilides and their derivates as perspective anti-tuberculosis drugs: Synthetic routes and biological evaluations. Mini Rev. Org. Chem. 2011, 8, 211-220. [CrossRef]

12. Kratky, M.; Vinsova, J. Antiviral activity of substituted salicylanilides-A review. Mini Rev. Med. Chem. 2011, 11, 956-967. [CrossRef] [PubMed]

13. Kratky, M.; Vinsova, J. Advances in mycobacterial isocitrate lyase targeting and inhibitors. Curr. Med. Chem. 2012, 19, 6126-6137. [CrossRef] [PubMed]

14. Gonec, T.; Kos, J.; Zadrazilova, I.; Pesko, M.; Keltosova, S.; Tengler, J.; Bobal, P.; Kollar, P.; Cizek, A.; Kralova, K.; et al. Antimycobacterial and herbicidal activity of ring-substituted 1-hydroxynaphthalene2-carboxanilides. Bioorg. Med. Chem. 2013, 21, 6531-6541. [CrossRef] [PubMed]

15. Zadrazilova, I.; Pospisilova, S.; Pauk, K.; Imramovsky, A.; Vinsova, J.; Cizek, A.; Jampilek, J. In vitro bactericidal activity of 4- and 5-chloro-2-hydroxy- $N$-[1-oxo-1-(phenylamino)alkan-2-yl]benzamides against MRSA. BioMed Res. Int. 2015, 2015, 349534. [CrossRef] [PubMed]

16. Zadrazilova, I.; Pospisilova, S.; Masarikova, M.; Imramovsky, A.; Monreal-Ferriz, J.; Vinsova, J.; Cizek, A.; Jampilek, J. Salicylanilide carbamates: Promising antibacterial agents with high in vitro activity against methicillin-resistant Staphylococcus aureus. Eur. J. Pharm. Sci. 2015, 77, 197-207. [CrossRef] [PubMed]

17. Kushkevych, I.; Kollar, P.; Ferreira, A.L.; Palma, D.; Duarte, A.; Lopes, M.M.; Bartos, M.; Pauk, K.; Imramovsky, A.; Jampilek, J. Antimicrobial effect of salicylamide derivatives against intestinal sulfate-reducing bacteria. J. Appl. Biomed. 2016, 14, 125-130. [CrossRef]

18. Steinhilber, D.; Schubert-Zsilavecz, M.; Roth, H.J. Medizinische Chemie: Targets, Arzneistoffe, Chemische Biologie; Deutscher Apotheker Verlag: Stutgart, Germany, 2010.

19. US Environmental Protection Agency-Pesticide Registration: Pesticide Data Submitters List (PDSL), 2016. Available online: https://www.epa.gov/sites/production/files/2016-04/documents/dslchem_0.pdf (accessed on 30 July 2016).

20. Pattabiraman, V.R.; Bode, J.W. Rethinking amide bond synthesis. Nature 2011, 480, 471-479. [CrossRef] [PubMed]

21. Ghosh, A.K.; Brindisi, M. Organic carbamates in drug design and medicinal chemistry. J. Med. Chem. 2015, 58, 2895-2940. [CrossRef] [PubMed]

22. Otevrel, J.; Mandelova, Z.; Pesko, M.; Guo, J.; Kralova, K.; Sersen, F.; Vejsova, M.; Kalinowski, D.; Kovacevic, Z.; Coffey, A.; et al. Investigating the spectrum of biological activity of ring-substituted salicylanilides and carbamoylphenylcarbamates. Molecules 2010, 15, 8122-8142. [CrossRef] [PubMed]

23. Imramovsky, A.; Pesko, M.; Kralova, K.; Vejsova, M.; Stolarikova, J.; Vinsova, J.; Jampilek, J. Investigating spectrum of biological activity of 4- and 5-chloro-2-hydroxy- $\mathrm{N}$-[2-(arylamino)-1-alkyl-2-oxoethyl]-benzamides. Molecules 2011, 16, 2414-2430. [CrossRef] [PubMed] 
24. Imramovsky, A.; Pesko, M.; Monreal-Ferriz, J.; Kralova, K.; Vinsova, J.; Jampilek, J. Photosynthesis-inhibiting efficiency of 4-chloro-2-(chlorophenylcarbamoyl)phenyl alkyl-carbamates. Bioorg. Med. Chem. Lett. 2011, 21, 4564-4567. [CrossRef] [PubMed]

25. Jampilek, J.; Brychtova, K. Azone analogues: Classification, design, and transdermal penetration principles. Med. Res. Rev. 2012, 32, 907-947. [CrossRef] [PubMed]

26. Malik, I.; Bukovsky, M.; Andriamainty, F.; Galisinova, J. Anti-microbial activity of meta-alkoxyphenylcarbamates containing substituted N-phenylpiperazine fragment. Braz. J. Microbiol. 2012, 43, 959-965. [PubMed]

27. Malik, I.; Bukovsky, M.; Andriamainty, F.; Galisinova, J. Antimicrobial effect of para-alkoxyphenylcarbamic acid esters containing substituted N-phenylpiperazine moiety. Braz. J. Microbiol. 2013, 44, 457-463. [CrossRef] [PubMed]

28. Zumla, A.; Nahid, P.; Cole, S.T. Advances in the development of new tuberculosis drugs and treatment regimens. Nat. Rev. Drug Discov. 2013, 12, 388-404. [CrossRef] [PubMed]

29. Kos, J.; Zadrazilova, I.; Pesko, M.; Keltosova, S.; Tengler, J.; Gonec, T.; Bobal, P.; Kauerova, T.; Oravec, M.; Kollar, P.; et al. Antibacterial and herbicidal activity of ring-substituted 3-hydroxynaphthalene2-carboxanilides. Molecules 2013, 18, 7977-7997. [CrossRef] [PubMed]

30. Gonec, T.; Kos, J.; Zadrazilova, I.; Pesko, M.; Govender, R.; Chambel, B.; Pereira, D.; Kollar, P.; Imramovsky, A.; O'Mahony, J.; et al. Antibacterial and herbicidal activity of ring-substituted 2-hydroxynaphthalene1-carboxanilides. Molecules 2013, 18, 9397-9419. [CrossRef] [PubMed]

31. Jampilek, J. Recent advances in design of potential quinoxaline anti-infectives. Curr. Med. Chem. 2014, 21, 4347-4373. [CrossRef] [PubMed]

32. Gonec, T.; Kos, J.; Nevin, E.; Govender, R.; Pesko, M.; Kushkevych, I.; Oravec, M.; Kollar, P.; O’Mahony, J.; Kralova, K.; et al. Preparation and biological properties of ring-substituted naphthalene-1-carboxanilides. Molecules 2014, 19, 10386-10409. [CrossRef] [PubMed]

33. Gonec, T.; Zadrazilova, I.; Nevin, E.; Kauerova, T.; Pesko, M.; Kos, J.; Oravec, M.; Kollar, P.; Coffey, A.; O'Mahony, J.; et al. Synthesis and biological evaluation of $\mathrm{N}$-alkoxyphenyl-3-hydroxynaphthalene2-carboxanilides. Molecules 2015, 20, 9767-9787. [CrossRef] [PubMed]

34. Kralova, K.; Perina, M.; Waisser, K.; Jampilek, J. Structure-activity relationships of N-benzylsalicylamides for inhibition of photosynthetic electron transport. Med. Chem. 2015, 11, 156-164. [CrossRef] [PubMed]

35. Kauerova, T.; Kos, J.; Gonec, T.; Jampilek, J.; Kollar, P. Antiproliferative and pro-apoptotic effect of novel nitro-substituted hydroxynaphthanilides on human cancer cell lines. Int. J. Mol. Sci. 2016, 17, 1219. [CrossRef] [PubMed]

36. Gonec, T.; Pospisilova, S.; Kauerova, T.; Kos, J.; Dohanosova, J.; Oravec, M.; Kollar, P.; Coffey, A.; Liptaj, T.; Cizek, A.; et al. $\mathrm{N}$-alkoxyphenylhydroxynaphthalenecarboxamides and their antimycobacterial activity. Molecules 2016, 21, 1068. [CrossRef] [PubMed]

37. Pauk, K.; Zadrazilova, I.; Imramovsky, A.; Vinsova, J.; Pokorna, M.; Masarikova, M.; Cizek, A.; Jampilek, J. New derivatives of salicylamides: Preparation and antimicrobial activity against various bacterial species. Bioorg. Med. Chem. 2013, 21, 6574-6581. [CrossRef] [PubMed]

38. Alnimr, A.M. Dormancy models for Mycobacterium tuberculosis: A mini review. Braz. J. Microbiol. 2015, 46, 641-647. [CrossRef] [PubMed]

39. Van Ingen, J.; Boeree, M.J.; van Soolingen, D.; Mouton, J.W. Resistance mechanisms and drug susceptibility testing of nontuberculous mycobacteria. Drug Resist. Updates 2012, 15, 149-161. [CrossRef] [PubMed]

40. Matveychuk, A.; Fuks, L.; Priess, R.; Hahim, I.; Shitrit, D. Clinical and radiological features of Mycobacterium kansasii and other NTM infections. Resp. Med. 2012, 106, 1472-1477. [CrossRef] [PubMed]

41. National Committee for Clinical Laboratory Standards. M24-A2 Susceptibility Testing of Mycobacteria, Nocardiae, and Other Aerobic Actinomycetes; Approved Standard, 2nd ed.; NCCLS: Wayne, PA, USA, 2011.

42. Tengler, J.; Kapustikova, I.; Pesko, M.; Govender, R.; Keltosova, S.; Mokry, P.; Kollar, P.; O’Mahony, J.; Coffey, A.; Kralova, K.; et al. Synthesis and biological evaluation of 2-hydroxy-3-[(2-aryloxyethyl)amino]propyl 4-[(alkoxycarbonyl)amino]benzoates. Sci. World J. 2013, 2013, 274570. [CrossRef] [PubMed]

43. Kratky, M.; Vinsova, J. Salicylanilide $N$-monosubstituted carbamates: Synthesis and in vitro antimicrobial activity. Bioorg. Med. Chem. 2016, 24, 1322-1330. [CrossRef] [PubMed]

44. Kos, J.; Nevin, E.; Soral, M.; Kushkevych, I.; Gonec, T.; Bobal, P.; Kollar, P.; Coffey, A.; O’Mahony, J.; Liptaj, T.; et al. Synthesis and antimycobacterial properties of ring-substituted 6-hydroxynaphthalene2-carboxanilides. Bioorg. Med. Chem. 2015, 23, 2035-2043. [CrossRef] [PubMed] 
45. Suffness, M.; Douros, J. Current status of the NCI plant and animal product program. J. Nat. Prod. 1982, 45, 1-14. [CrossRef] [PubMed]

46. National Committee for Clinical Laboratory Standards. Methods for Dilution Antimicrobial Susceptibility Tests for Bacteria that Grow Aerobically; Approved Standard, 5th ed.; CLSI Document M7-A5; NCCLS: Wayne, PA, USA, 2000.

47. National Committee for Clinical Laboratory Standards. Performance Standards for Antimicrobial Susceptibility Testing; 12th Informational Supplement M100-S12; NCCLS: Wayne, MI, USA, 2002.

48. Schwalbe, R.; Steele-Moore, L.; Goodwin, A.C. Antimicrobial Susceptibility Testing Protocols; CRC Press: Boca Raton, FL, USA, 2007.

49. Clinical and Laboratory Standards Institute. Available online: http://www.clsi.org (accessed on 5 September 2016).

Sample Availability: Samples of compounds 1-28 are available from authors T. Gonec, J. Stranik, J. Kos, J. Jampilek.

(C) 2016 by the authors; licensee MDPI, Basel, Switzerland. This article is an open access article distributed under the terms and conditions of the Creative Commons Attribution (CC-BY) license (http://creativecommons.org/licenses/by/4.0/). 